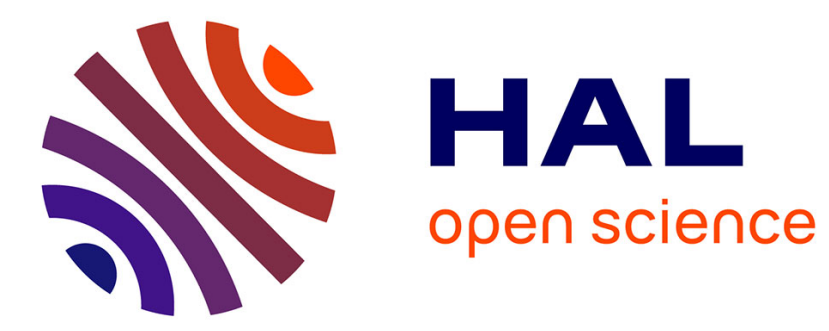

\title{
Hydrogenating activity of Pt/zeolite catalysts focusing acid support and metal dispersion influence
}

Pedro S. Mendes, Grégory Lapisardi, Christophe Bouchy, Mickaël Rivallan, Joao M. Silva, Filipa M. Ribeiro

\section{- To cite this version:}

Pedro S. Mendes, Grégory Lapisardi, Christophe Bouchy, Mickaël Rivallan, Joao M. Silva, et al.. Hydrogenating activity of $\mathrm{Pt} /$ zeolite catalysts focusing acid support and metal dispersion influence. Applied Catalysis A : General, 2015, 504, pp.17-28. 10.1016/j.apcata.2015.03.027 . hal-01223679

\section{HAL Id: hal-01223679 \\ https://hal.science/hal-01223679}

Submitted on 26 Nov 2015

HAL is a multi-disciplinary open access archive for the deposit and dissemination of scientific research documents, whether they are published or not. The documents may come from teaching and research institutions in France or abroad, or from public or private research centers.
L'archive ouverte pluridisciplinaire HAL, est destinée au dépôt et à la diffusion de documents scientifiques de niveau recherche, publiés ou non, émanant des établissements d'enseignement et de recherche français ou étrangers, des laboratoires publics ou privés. 


\section{Hydrogenating activity of Pt/zeolite catalysts focusing acid support and metal dispersion influence}

Pedro S. F. Mendes ${ }^{\mathrm{a}, \mathrm{b}}$, Grégory Lapisardi ${ }^{\mathrm{b}}$, Christophe Bouchy ${ }^{\mathrm{b}}$, Mickaël Rivallan ${ }^{\mathrm{b}}$, João M. Silva ${ }^{\mathrm{a}, \mathrm{c}}$, M. Filipa Ribeiro ${ }^{\mathrm{a} *}$

${ }^{a}$ CQE, Instituto Superior Técnico, Universidade de Lisboa, Av. Rovisco Pais, 1049-001 Lisboa, Portugal

${ }^{b}$ IFP Energies nouvelles, Rond-point de l'échangeur de Solaize, BP 3, 69360 Solaize, France

${ }^{c} A D E Q$, Instituto Superior de Engenharia de Lisboa - ISEL, R. Cons. Emídio Navarro, 1959-007 Lisboa, Portugal

*filipa.ribeiro@tecnico.ulisboa.pt; +351 218147872

\section{Abstract}

Toluene hydrogenation was studied over catalysts based on Pt supported on large pore zeolites (HUSY and HBEA) with different metal/acid ratios. Acidity of zeolites was assessed by pyridine adsorption followed by FTIR showing only small changes before and after Pt introduction. Metal dispersion was determined by $\mathrm{H}_{2}-\mathrm{O}_{2}$ titration and verified by a linear correlation with the intensity of $\mathrm{Pt}^{0}-\mathrm{CO}$ band obtained by in situ FTIR. It was also observed that the electronic properties of $\mathrm{Pt}^{0}$ clusters were similar for the different catalysts. Catalytic tests showed rapid catalyst deactivation with an activity loss of $80-95 \%$ after 60 min. of reaction. The turnover frequency of fresh catalysts depended both on metal dispersion and the support. For the same support, it changed by a 1.7-fold (HBEA) and 4.0-fold (HUSY) showing that toluene hydrogenation is structure-sensitive, i.e. hydrogenating activity is not a unique function of accessible metal. This was proposed to be due to the contribution to the overall activity of the hydrogenation of adsorbed toluene on acid sites via hydrogen spillover. Taking into account the role of zeolite acidity, the catalysts series were compared by the activity per total adsorbing sites which was observed to increase steadily with $n_{\mathrm{Pt}} /\left(\mathrm{n}_{\mathrm{Pt}}+\mathrm{n}_{\mathrm{A}}\right)$. An increase of the accessible Pt atoms leads to an increase on the amount of spilled over 
hydrogen available in acid sites therefore increasing the overall activity. Pt/HBEA catalysts were found to be more active per total adsorbing site than Pt/HUSY which is proposed to be due to an augmentation in the efficiency of spilled over hydrogen diffusion related to the proximity between Pt clusters and acid sites. The intervention of Lewis acid sites in a greater extent than that measured by pyridine adsorption may also contribute to this higher activity of Pt/HBEA catalysts. These results reinforce the importance of model reactions as a closer perspective to the relevant catalyst properties in reaction conditions.

Keywords: Platinum; HUSY; HBEA; toluene hydrogenation; FTIR

\section{Introduction}

Zeolites have a prime role as catalysts in petroleum refining industry [1], due to their interconnected channel systems or hierarchical structure combining micro and mesopores and acid-basic properties which can be tuned through synthesis or postsynthesis treatments [2, 3]. The ionic exchange capacity of zeolites has led to their use as adsorbents and has also a key role in catalysis regarding the support characteristics and dispersion of metal nanoparticles.

Most of the catalytic processes in the petroleum refining industry use bifunctional catalysts comprising a combination of acid and hydrogenation-dehydrogenation functions. From a chemical point of view, bifunctional catalysts ability to generate carbenium ions at relatively low temperatures comparing to monofunctional acidic catalysts [4] explains their key role in industry. The acidity can be provided by a zeolite, while the hydrogenation-dehydrogenation activity is exerted by finely dispersed (noble or transition) metals. Among all the bifunctional catalysts used, noble metals supported on zeolites (usually mixed with alumina) have a great variety of applications. In particular, hydroisomerization of $\mathrm{C}_{5}-\mathrm{C}_{6} n$-paraffins to produce high-octane gasoline as (partial) substitute of MTBE and of long chain $n$-paraffins applied in the conversion of these paraffins from heavy oils (catalytic dewaxing) to produce lubricating oils with good cold-flow properties and hydroconversion of synthetic wax produced through the Fischer-Tropsch process [5-8]. These catalysts can also be used in hydrocracking 
processes depending on the desired products, the type of feedstock and partial pressure of sulphurated contaminants. Regarding the support, catalysts based on Y zeolite are the most studied due to their unique importance in industrial catalysts [9]. Some other zeolites, like BEA one, have been also considerably studied [10], including advantageous performance comparatively to Y zeolite-based catalysts [11-14].

Most of the aspects that affect the performances of bifunctional catalysts have been studied and are accessible in a series of papers published along last decades [15-20] and more recently in two reviews published by Weitkamp [21] and Guisnet [22]. Special attention has been dedicated to the metal-acid balance and its influence on the product distribution, activity and stability of Pt/zeolite catalysts [20]. According to the literature, in a general way, a good balance can be obtained with $0.4-0.6 \% \mathrm{Pt}[10,23]$. For hydrocracking, the concept of ideal hydrocracking catalyst was based on studies over Pt/HUSY [15-17] that showed products distribution as a unique function of conversion for bifunctional catalyst in which the acid function was limiting, in agreement with the reaction mechanism proposed firstly by Weisz [24] and Coonradt and Garwood [25] for $n$-alkane hydroconversion over bifunctional catalysts. Recently, the importance of the degree of intimacy between both functions on the catalyst performance, as proposed by Weisz [24], was reinforced by studies over Pt/HBEA catalysts [26, 27].

Taking into account the influence of metal and acid functions on the activity of bifunctional catalysts, the characterization of these catalysts must be based in a precise knowledge of the properties of the hydrogenating and the acid sites as well as their relative activities. Classical characterization methods to evaluate both the hydrogenating (e.g. $\mathrm{H}_{2}$ chemisorption [28] or $\mathrm{CO}$ adsorption [29]) and the acid functions (e.g. temperature-programmed desorption of ammoniac [30] or pyridine adsorptiondesorption followed by FT-IR [31]) take place under operating conditions very different from those of the reactors either in laboratory or industry. The quantitative information about surface properties are obtained indirectly by the use of probe molecules that are very often much smaller than the reactants of interest. In this way, model reactions can be crucial towards a comprehensive understanding of the fundamental phenomena occurring in complex catalytic systems. In terms of metal activity, the hydrogenation of one-ring aromatic compounds (as benzene or toluene) has been proved to be well suited as it reproduces the accessibility and location of the metal sites and has only one 
product of reaction [32, 33]. Confrontation of the performance observed in catalytic test with concentrations sites (acidic and metallic sites) measured by conventional spectroscopic methods are of great interest. It also explains why "operando" coupling techniques are nowadays gaining more and more attention for the understanding of the developed catalysts.

The significant amount of work already published in literature on one-ring aromatics hydrogenation results in a very diverse and contradictory range of conclusions [32]. A major contribution for this field was given by Vannice and co-workers that showed that Pt was 27 times more active than Pd and that support could also play a role, as activity changed based on the support acidity $\left(\mathrm{SiO}_{2}-\mathrm{Al}_{2} \mathrm{O}_{3}>\mathrm{TiO}_{2}>\eta-\mathrm{Al}_{2} \mathrm{O}_{3}=\mathrm{SiO}_{2}\right)$ [34], proposing that the enhanced activity between the supports was caused by spilled-over hydrogen reaction with toluene adsorbed on the oxide surface at the metal-interfacial region [34, 35]. Therefore, the overall activity could be separated into that from the metal surface and that from the interfacial region [34]. On the other hand, results on zeolite-based catalysts have been scarce as a consequence of their low applicability in terms of industrial aromatics hydrogenation due to quick deactivation by coke formation. Furthermore, the modest sum of studies published either compares a zeolite with a lower acidic support or do not present a comprehensive characterization of both metal and acid sites. The lack of exploitation of some published results in terms of properties-activity relationships also restricts the practice of toluene hydrogenation as a model reaction for metal-supported catalysts. For instance, the study of Chupin and coworkers has some very relevant data on a series of Pt/HUSY catalysts [33], but the focus was held on the deactivation mechanisms.

In summary, toluene hydrogenation can be very useful to characterize bifunctional catalysts, but the literature is mostly based on weaker acid solids than zeolites and is very limited in comparing different amounts of accessible metal on a same zeolite and even scarcer in terms of comparing different zeolites and the influence of their properties on the catalytic activity. Therefore, this work aims to enlighten the behavior of $\mathrm{Pt} /$ zeolite catalysts that are quite relevant in petroleum refining industry on the hydrogenation of toluene in terms of both support and metal properties thanks to their comprehensive characterization and by covering a reasonable range of metal/acid ratios. In this way, we intend that our results support the use of toluene hydrogenation as a 
model reaction to get a more faithful idea about bifunctional catalysts than the classical characterization techniques.

\section{Experimental}

\subsection{Catalysts preparation}

Commercial zeolites HUSY (CBV720) and $\mathrm{NH}_{4}$-BEA (CP814E) were supplied by Zeolyst. $\mathrm{NH}_{4}$-BEA zeolite was calcined to obtain the protonic form using a protocol published elsewhere [36]. The introduction of platinum in the supports was performed by incipient wetness impregnation of $\left[\mathrm{Pt}\left(\mathrm{NH}_{3}\right)_{4} \mathrm{NO}_{3}\right] \cdot 6 \mathrm{H}_{2} \mathrm{O}$ resulting in three $\mathrm{Pt}$ contents: $0.1,0.4$ and $0.7 \mathrm{wt} \%$. The impregnated material was dried overnight at $110^{\circ} \mathrm{C}$ and then calcined in an air flow of $4 \mathrm{~L} \mathrm{~h}^{-1} \mathrm{~g}^{-1}$. Three plateaux at 423, 523 and $623 \mathrm{~K}$ over $1 \mathrm{~h}$ each and a final plateau at $773 \mathrm{~K}$ over $2 \mathrm{~h}$ were performed. A heating rate of 5 $\mathrm{K} \min ^{-1}$ was used. Ex-situ reduction was performed to ensure a stable and consistent platinum phase to all the catalytic tests and characterization techniques. Reduction included two plateaux: $393 \mathrm{~K}$ over $1 \mathrm{~h}$ and $723 \mathrm{~K}$ over $2 \mathrm{~h}$ using a heating rate of $5 \mathrm{~K}$ $\min ^{-1}$ and under a hydrogen flow of $4 \mathrm{~L} \mathrm{~h}^{-1} \mathrm{~g}^{-1}$.

\subsection{Catalysts Characterisation}

Parent zeolites were characterized by x-Ray Fluorescence to determine the total Si/Al ratio and by ${ }^{27} \mathrm{Al}$ magic angle spinning nuclear magnetic resonance (MAS-NMR) to determine the percentage of aluminium that is in the framework. The experiments were performed using a Bruker 400 Avance spectrometer equipped with a $4 \mathrm{~mm}$ CP MAS probe head at room temperature. The MAS rate was $12 \mathrm{kHz}$ for all experiments. The ${ }^{27} \mathrm{Al}$ NMR spectra were obtained using exciting pulses of $1 \mu \mathrm{s}(\pi / 12)$ and relaxation delays of $0.5 \mathrm{~s}$.

Nitrogen adsorption measurements were carried out at $77 \mathrm{~K}$ on a Micrometrics ASAP 2010 apparatus. Before adsorption, zeolite samples were degassed under vacuum at 90 ${ }^{\circ} \mathrm{C}$ for $1 \mathrm{~h}$ and then at $623 \mathrm{~K}$ for $4 \mathrm{~h}$. The total porous volume $\left(\mathrm{V}_{\text {total }}\right)$ was calculated from the adsorbed volume of nitrogen for a relative pressure $\mathrm{P} / \mathrm{P}_{0}$ of 0.97 whereas the 
microporous volume $\left(\mathrm{V}_{\text {micro }}\right)$ and the external surface area $\left(\mathrm{S}_{\text {ext }}\right)$ were determined using the $t$-plot method [37]. The mesoporous volume $\left(\mathrm{V}_{\text {meso }}\right)$ was obtained by the difference between $\mathrm{V}_{\text {total }}$ and $\mathrm{V}_{\text {micro }}$.

Pyridine adsorption experiments were performed with a static experimental setup under vacuum. A homemade IR cell equipped with $\mathrm{KBr}$ windows was used. The catalyst powder was pressed into self-supporting wafers (20 mg, $10 \mathrm{mg} \mathrm{cm}^{-2}$ ). The samples were activated in static conditions under secondary vacuum at $723 \mathrm{~K}$. After cooling at room temperature, pressure of 4 mbar of pyridine was introduced in contact to the activated sample. IR spectra of thermo desorbed sample at 423, 523, 623 and $723 \mathrm{~K}$ were recorded in order to get information on the acidic surface properties of the material (concentration, strength and accessibility of acid sites).

Platinum dispersion was determined by hydrogen titration of chemisorbed oxygen in an Autochem II 2920 (Micromeritics) apparatus with a thermal conductivity detector: prereduced saturated samples (200-300 mg) were pre-treated under $\mathrm{H}_{2}\left(30 \mathrm{~mL} \mathrm{~min}^{-1}\right)$ at $473 \mathrm{~K}$ over $30 \mathrm{~min}$ and $723 \mathrm{~K}$ over $60 \mathrm{~min}$ using a heating rate of $5 \mathrm{~K} \mathrm{~min}^{-1}$, cooled under $\mathrm{H}_{2}$ to room temperature and purged under $\operatorname{Ar}\left(20 \mathrm{~mL} \mathrm{~min}^{-1}\right)$ over the night. Two cycles of oxygen titration of chemisorbed hydrogen (He as carrier at $25 \mathrm{~mL} \mathrm{~min}^{-1}$ ) and hydrogen titration of chemisorbed oxygen ( $\mathrm{Ar}$ as carrier at $30 \mathrm{~mL} \mathrm{~min}{ }^{-1}$ ) were consecutively performed to verify the repeatability of measures according to the recommendations in literature [28]. Chemisorption was performed at $308 \mathrm{~K}$ using an injection loop of $0.07 \mathrm{~mL}$ and pulses of $\mathrm{H}_{2}\left(\right.$ or $\left.\mathrm{O}_{2}\right)$ were injected every $3 \mathrm{~min}$. The results presented correspond to the average $\mathrm{H}_{2}$ consumption in the two cycles, with a maximum relative deviation between measures of $8 \%$. The metal dispersion was calculated by means of $1.5 \mathrm{H}_{2}$ :Pt stoichiometric coefficient [28, 38]. The average size of Pt particles was estimated using a shape factor for a cube with one side non-exposed ( $F$ = 5) as recommended in literature for supported metal particles [39].

Transmission electron microscopy TEM and high-angle annular dark-field scanning transmission electron microscopy HAADF-STEM observations were performed using a JEOL JEM 2100F microscope operated at $200 \mathrm{kV}$. Samples were embedded in an epoxy resin, and thin slices (about $70 \mathrm{~nm}$ ) were cut by ultramicrotomy and transferred onto a cooper grid covered by a carbon holey membrane. 
CO chemisorption experiments were performed with a static experimental setup under vacuum. A homemade IR cell equipped with $\mathrm{KBr}$ windows was used. The catalyst powder was pressed into self-supporting wafers (20 mg, $10 \mathrm{mg} \mathrm{cm}^{-2}$ ). The samples were activated in static conditions under $\mathrm{H}_{2}$ at $723 \mathrm{~K}$ followed by evacuation (repeated twice). After cooling at room temperature, doses of CO were progressively added in contact to the reduced sample, leading to an increase in the intensity of carbonyls IR bands of CO chemisorbed on Pt surface atoms until saturation.

\subsection{Catalytic Tests}

The toluene hydrogenation was performed at $383 \mathrm{~K}$ under atmospheric pressure using a pyrex glass down-flow reactor designed with a minimum volume so the residence time is small enough to have distinct products compositions in small intervals of reaction time. Reactor effluent was recovered at each $30 \mathrm{~s}$, from $1 \mathrm{~min}$ to $3 \mathrm{~min}$ of reaction, and at 5, 10, 15, 30 and 60 min thanks to a multiposition Valco valve and analysed in a gas chromatograph (GC) equipped with a 50 m HP-PONA capillary column from Agilent Technologies and a flame ionization detector (FID). The entire downstream from the reactor exit until the GC (including the multiposition valve) was heated at about $423 \mathrm{~K}$ to prevent products condensation. Before reaction, catalysts were pre-treated under $\mathrm{H}_{2}$ $\left(16 \mathrm{NL} \mathrm{h}^{-1} \mathrm{~g}^{-1}\right.$ ) at $473 \mathrm{~K}$ over $30 \mathrm{~min}$ and $723 \mathrm{~K}$ over $60 \mathrm{~min}$ using a heating rate of $5 \mathrm{~K}$ $\min ^{-1}$. Operating conditions are based on those used by Chupin and co-workers [33], but with some adaptations. Thus, the hydrogen to toluene molar ratio of 45 was maintained, but the toluene to $n$-hexane molar ratio was 4.0. Toluene weight hour space velocity (WHSV) was chosen in order to keep initial conversion lower than $15 \%$ for each catalyst. Total pressure of the reactor was kept constant as changes in WHSV (17-54 $\mathrm{h}^{-}$ ${ }^{1}$ ) were achieved by reduction of catalyst weight by dilution with quartz (both with a particle size of 0.20-0.35 mm). In that way, the $\mathrm{H}_{2}$ flow was $5.55 \mathrm{NL} \mathrm{h}^{-1}$ and liquid feed flow (n-hexane + toluene) was $3.5 \mathrm{~mL} \mathrm{~h}^{-1}$. The catalytic activity at each time was calculated as the toluene consumption per catalyst gram. Turnover frequencies were calculated as the ratio of catalytic activity to the (molar) amount of accessible Pt per catalyst gram measured by $\mathrm{H}_{2}-\mathrm{O}_{2}$ titration. Activity per total adsorbing sites was calculated as the ratio of catalytic activity to the sum of the (molar) amount of accessible Pt per catalyst gram and the total acid sites (molar) per catalyst gram measured by pyridine adsorption at $423 \mathrm{~K}$ followed by FTIR. The deactivation rate was 
calculated as ratio of the loss of activity from $t=1$ min to $t=60$ min to the activity at $t=1$ $\min$.

\section{Results}

\subsection{Physico-chemical and acidic properties of catalysts}

The structural and textural properties of parent zeolites are depicted on Table 1. HBEA zeolite has higher mesoporous and total porous volumes than HUSY, as well as higher external surface, but lower microporous volume. Framework Si/Al (determined by ${ }^{27} \mathrm{Al}$ NMR and XRF results) is similar for both zeolites resulting in an analogous $\mathrm{H}^{+}$ concentration obtained through the estimated unit cell formula. On the contrary, extraframework aluminium (EFAL) species were estimated to be around three times higher for HBEA zeolite than for HUSY. It is worthy to note that $\mathrm{NH}_{4}$-BEA zeolite was calcined to the protonic form to obtain consistent HBEA samples as it is known to be unusually sensitive to calcination and ion-exchange conditions [40-42]. In this way, all the results presented are for calcined BEA zeolite.

IR spectra of Pt/HUSY and Pt/HBEA and corresponding supports (HUSY and HBEA) after activation at $723 \mathrm{~K}$ are reported in Figure 1 and Figure 2 respectively. HUSY series exhibits at least six $\mathrm{OH}$ stretching modes centred at 3744, 3672, 3630, 3602, 3566 and $3525 \mathrm{~cm}^{-1}$, due to different crystallographic positions of $\mathrm{OH}$ groups attached to the framework and to EFAL species. The intense band observed at $3745 \mathrm{~cm}^{-1}$ is assigned to non-acidic silanol (SiOH) groups. The IR components at 3630 and $3566 \mathrm{~cm}^{-1}$ are due to hydroxyl groups within the supercages and small cavities, denoted HF and LF respectively. These two sites correspond to Brønsted acid centers and are able to react with pyridine (vide infra). The two shoulders observed at 3602 and $3525 \mathrm{~cm}^{-1}$ originated from the two later hydroxyl groups (HF and LF), exhibit a superacidity after perturbation by EFAL silicoaluminous debris [43]. The weak band at $3672 \mathrm{~cm}^{-1}$, generally attributed to $\mathrm{OH}$ groups located into the large cavities for non dealuminated HUSY zeolite, is here ascribed to hydroxyls attached to EFAL (AlOH) species, or to proton compensating $\mathrm{AlO}_{4}$ tetrahedra, where $\mathrm{Al}$ atom is still partly bonded to the zeolite framework. 
HBEA series (Figure 2) displays in the hydroxyl region four components centered at 3781, 3744 - 3737, 3665 and $3610 \mathrm{~cm}^{-1}$, due to different $\mathrm{OH}$ groups attached to the framework and to EFAL species [44]. As for HUSY zeolite, the intense band observed at $3744 \mathrm{~cm}^{-1}$ and shoulder at $3737 \mathrm{~cm}^{-1}$ are assigned to non-acidic silanol (SiOH) groups. The band at $3665 \mathrm{~cm}^{-1}$ originated from $\mathrm{OH}$ groups attached to EFAL species or to Al bound only by one or two bonds to the framework. This component is relatively intense when compared to data reported in the literature [45]. The component at 3610 $\mathrm{cm}^{-1}$ is due to $\mathrm{Si}(\mathrm{OH}) \mathrm{Al}$ groups and exhibit Brønsted acidity. The well defined contribution at $3782 \mathrm{~cm}^{-1}$ corresponds to terminal $\mathrm{OH}$ groups of aluminol in transient state species (leaving the framework) [46].

The wavenumbers and intensities of the bands at $3665 \mathrm{~cm}^{-1}$ and $3610 \mathrm{~cm}^{-1}$ were represented as function of Pt content for HBEA and Pt/HBEA catalysts (Figure 3). After introduction of Pt atoms in the porosity and on the external surface of HBEA zeolite, short modifications of the hydroxyl can be observed. The contribution at $3606 \mathrm{~cm}^{-}$ ${ }^{1}$ related with Brønsted acidity is affected by Pt introduction, which could indicate ion exchange process by Pt atoms and/or perturbation by Pt clusters in the close vicinity of the $\mathrm{OH}$. On the other hand, the intensity of the contribution at $3665 \mathrm{~cm}^{-1}$ assigned to $\mathrm{OH}$ groups on EFAL species is almost constant. Both $\mathrm{OH}$ contributions are slightly shifted to high wavenumbers for increased Pt loadings which may confirm the proximity between Pt nanoparticles and OH groups. Concerning HUSY series, similar analysis of the IR spectra before and after Pt introduction does not show significant trends (Figure 4).

Pyridine adsorption on Pt free and 0.7 wt.\% Pt HBEA and HUSY zeolites and consecutive thermodesorption have been followed by in situ FTIR in order to determine the acidic surface properties of the initial supports and to evaluate the effect of Pt introduction. For the four different materials, the interaction of pyridine results in i) total consumption of hydroxyl groups from Brønsted acid sites which indicate that all sites are accessible to pyridine, ii) perturbations of $\mathrm{SiOH}$ silanols and $\mathrm{AlOH}$ aluminols, concomitantly with appearance of IR components in the range 1650-1440 $\mathrm{cm}^{-1}$ (for brevity, IR spectra of the $\mathrm{vOH}$ and $\mathrm{vCN}$ regions are not reported). The band around $1540 \mathrm{~cm}^{-1}$ characteristic for pyridinium ions (Brønsted acid sites, BAS) is linearly correlated with the corresponding contribution observed in the $\mathrm{OH}$ region at 3610 and 
3630 - $3530 \mathrm{~cm}^{-1}$ for HBEA and HUSY respectively; while bands between 1445 and $1460 \mathrm{~cm}^{-1}$ are attributed to coordinatively adsorbed pyridine (Lewis acid sites, LAS) [47]. Quantification of the total number of acid sites BAS and LAS was calculated from the molar extinction coefficients reported in the literature elsewhere [31].

When comparing acidic properties of Pt free samples (Figure 5), HBEA zeolite exhibits two times the acid sites of HUSY zeolite ( $570 \mathrm{vs.} 290 \mu \mathrm{mol} / \mathrm{g}$ ), due to the 4-fold higher LAS concentration (350 vs. $90 \mu \mathrm{mol} / \mathrm{g}$ ). This much higher LAS concentration in HBEA zeolite is in line with the EFAL quantification obtained by ${ }^{27} \mathrm{Al}$ NMR (see Table 1 ). Moreover, about 50 to $69 \%$ of initial LAS are still in interaction with pyridine probe after thermodesorption at $723 \mathrm{~K}$ which implies the presence of relatively strong acid sites. Both materials report similar concentration of BAS (200 - $220 \mu \mathrm{mol} / \mathrm{g})$. Since all the hydroxyl groups are accessible to pyridine, the lower amount found by FTIR could be due to the presence of relatively weak BAS which are not probed anymore by pyridine after thermodesorption at $423 \mathrm{~K}$.

In order to understand the impact of Pt introduction on the acidic properties, pyridine adsorption has also been performed on $0.7 \mathrm{wt} \%$ Pt/HBEA and Pt/HUSY samples and the results have been compared to Pt free samples in Figure 5 that shows the evolution of concentration of BAS and LAS sites as a function of pyridine desorption temperature. After Pt introduction, total acidity (BAS + LAS) slightly decreased by $8 \%$ in the $0.7 \mathrm{Pt} / \mathrm{HBEA}$ and increased by $9 \%$ in the $0.7 \mathrm{Pt} / \mathrm{HUSY}$ sample resulting in a 1.7 fold higher acidity for the HBEA-based catalyst. For both catalysts, about $10 \%$ of BAS have been lost possibly due to Pt stabilisation on the zeolitic support via a small amount of cationic $\mathrm{Pt}^{2+}$ in exchange positions. These similar results for both zeolites series contrast with the distinct observations in the $\mathrm{OH}$ region. Therefore, the intensity decrease observed in the $\mathrm{OH}$ region for BAS contribution (Figure 3) of ca. $45 \%$ for HBEA sample with 0.7 wt.\% Pt could not be completely explained by Pt exchange. The proximity between Pt nanoparticles and $\mathrm{OH}$ groups seems to be the main cause for these features. When regarding the effect of Pt introduction on Lewis acidity of HBEA (Figure $5 \mathrm{~d}$ ), the concentration of LAS does not seem very affected, but the acidic strength seems nevertheless weakened compared to those reported on HBEA. For HUSY catalyst, a higher concentration in LAS is found after Pt incorporation (Figure 5 b). It could income from the ripening mechanism of Pt particles on HUSY microcrystals 
surface which could disrupt Si-O-Al links, yielding to an increase of EFAl species [48] and decreasing the overall Brønsted acidity of the zeolitic support.

In summary, few modifications are observed about the acidic strength but the initial concentrations in BAS and LAS are almost kept after Pt impregnation. It can be explained by the relatively low Pt content introduced and the preparation method (incipient wetness impregnation followed by calcination at $773 \mathrm{~K}$ and reduction at 723 $\mathrm{K})$.

\subsection{Metal properties}

The Pt content of all solids was determined by X-Ray Fluorescence spectroscopy showing a maximum deviation to the nominal value of $5 \%$. Results of hydrogen titration of chemisorbed oxygen are presented in Table 2. Results of Pt dispersion obtained are comprised between 30\% and 50\% meaning that these two acidic supports evidenced a medium capacity to stabilise small Pt particles (with the chosen impregnation protocol). In HBEA-based catalysts, dispersion decreases with increasing Pt content being that effect more visible from $0.4 \% \mathrm{Pt}$ to $0.7 \% \mathrm{Pt}$. On the contrary, in HUSY-based catalysts dispersion is rather similar for $0.4 \% \mathrm{Pt}$ and $0.7 \% \mathrm{Pt}$, but significantly lower for $0.1 \% \mathrm{Pt}$ which is unexpected as a lower Pt load should enable a larger dispersion of Pt on the support. Pt particle size calculated with $\mathrm{H}_{2}-\mathrm{O}_{2}$ titration results is between 1.8 and $3.0 \mathrm{~nm}$. This short range of particle size was rather expected according to literature: $3.0 \mathrm{~nm}$ is the mean size for Pt particles on zeolites up to $2 \%$ metal load [49].

Regarding adsorption of CO followed by FTIR (Figure 6 and Figure 7), IR components observed in the spectral region $2150-2000 \mathrm{~cm}^{-1}$ are typical from CO stretching mode when carbon monoxide is linearly adsorbed onto reduced $\mathrm{Pt}^{0}$ surface atoms species [29]. Short contributions can be nevertheless observed at lower wavenumbers ca. $1980 \mathrm{~cm}^{-1}$, due to the adsorption of one CO molecule on $n$ surface Pt atoms ( $n>1$; bridged species). It is worthy to note that, irrespectively of the zeolite, for 0.4 and $0.7 \mathrm{wt} . \% \mathrm{Pt}$ samples, a short contribution due to $\mathrm{CO}$ adsorbed on Pt atoms located in exchange position is observed in the spectra at $2150 \mathrm{~cm}^{-1}$ (in agreement with the $10 \%$ loss of initial BAS observed after $0.7 \%$ Pt introduction on both zeolites, see Figure 5). This fact 
reinforces once more the argument that the significant changes in the $\mathrm{OH}$ region spectral features of Pt/HBEA samples must be mostly due to the proximity between $\mathrm{Pt}$ and hydroxyl groups of HBEA zeolite.

For Pt/HBEA and Pt/HUSY samples, IR maxima appear at ca. $2097+/-1 \mathrm{~cm}^{-1}$. IR characterization by the means of $\mathrm{CO}$ probe technique is known to be sensitive to the particle size and metal support interactions, since it is affected by the electronic properties of Pt surface atoms [50]. Hence, strong metal support interactions may drastically shift the maxima to low wavenumbers. In the present case of study the dispersions and the particle size of the different catalysts are quite close (Table 2) and no significant difference in the position of the $\mathrm{v}_{\mathrm{CO}}$ maxima is observed. It could be consequently supposed that metal support interactions are almost alike for the whole set of Pt catalysts.

Additional spectroscopic features can be observed at $2228 \mathrm{~cm}^{-1}$ and $2189 \mathrm{~cm}^{-1}$ (the latter only for HBEA series). These species are observed on initial supports and could therefore not be assigned to oxidized Pt surface species. Pyridine adsorption measurements done on supports have highlighted the presence of very strong LAS, a possible attribution of the IR components at $2230-2180 \mathrm{~cm}^{-1}$ could be CO sorption on LAS (even at room temperature) [51].

Particle sizes have not been calculated from FTIR CO data [50]. Since the IR spectra of the reduced samples in contact with CO exhibit a symmetrical profile and in order to only consider the contribution of $\mathrm{Pt}^{\mathbf{0}}$ surface atoms of the nanoparticles, the intensity of the maxima at $2097 \mathrm{~cm}^{-1}$ has been used for the quantitative aspects. The intensity of the maxima measured at $2097 \mathrm{~cm}^{-1}$ for the different catalysts (Table 2) is indicative about the number of total Pt surface atoms of clusters accessible for CO chemisorption (the small contribution of Pt atoms present in exchange position at $2150 \mathrm{~cm}^{-1}$ is not taken into account). A linear correlation was found between the intensity of $\mathrm{Pt}^{\circ} \mathrm{CO}$ species and number of $\mathrm{Pt}$ atoms measured with $\mathrm{H}_{2}-\mathrm{O}_{2}$ titration technique with $\mathrm{R}^{2}=0.997$ (see Figure 8). The noteworthy goodness of fit relationship sustains the mutual consistency of the $\mathrm{H}_{2}-\mathrm{O}_{2}$ titration and $\mathrm{CO}$ chemisorption results. From these results, a correlation was obtained $\mathrm{n}_{\mathrm{Pt}}=269 \mathrm{~A}_{\mathrm{Pt}-\mathrm{CO}}$ for a $2 \mathrm{~cm}^{2}$ wafer with $17 \mathrm{mg}$ of solid. 
TEM analysis were performed on all samples and due to the low content of Pt and to the number of micrographs available no representative statistical distribution of particle size could be obtained for any sample. For HBEA series, the analysis of TEM and STEM micrographs evidences particles sizes in the range of 0.7-2.0 nm, 0.8-3.0 nm and 0.7-3.0 $\mathrm{nm}$ for $0.1,0.4$ and $0.7 \mathrm{wt} \% \mathrm{Pt}$, respectively. This is qualitatively in accordance with the results from $\mathrm{H}_{2}-\mathrm{O}_{2}$ titration that showed a slightly particle size increase with increasing Pt content. For HUSY series, particle size ranged in 0.8-2.9 nm for 0.4\%Pt/HUSY and in $0.7-2.5 \mathrm{~nm}$ for $0.7 \mathrm{Pt} / \mathrm{HUSY}$ which is also in accordance with $\mathrm{H}_{2}-\mathrm{O}_{2}$ titration results. For $0.1 \mathrm{Pt} / \mathrm{HUSY}$, in the available STEM micrographs it was not possible to find $\mathrm{Pt}$ particles. However, according to $\mathrm{H}_{2}-\mathrm{O}_{2}$ titration and $\mathrm{CO}$ chemisorption (and also catalytic results that are presented further on) it seems rather clear that a small particle population exists. The different imaging properties of HUSY and HBEA zeolites and the fact that this sample has the lowest number of Pt particles may explain this apparent absence of Pt particles. A number of STEM studies would be required to found, for this very low Pt content, the nanoparticles supported in HUSY zeolite. This was not, clearly, the subject of this study. Moreover, coherency between $\mathrm{H}_{2}-\mathrm{O}_{2}$ titration and $\mathrm{CO}$ chemisorption results seems to take away any reasonable doubt.

\subsection{Toluene hydrogenation}

Toluene hydrogenation was performed at constant hydrogen to toluene molar ratio (45), but the toluene WHSV was adjusted for each catalyst in order to keep initial conversion lower than $15 \%$ and to mitigate the possible thermal effects due to the exothermicity of the reaction. This influence was verified as, for example, over $0.7 \mathrm{Pt} / \mathrm{HUSY}$ catalyst a 1.5-fold raise in activity occurred passing from $15 \%$ to $75 \%$ conversion level. In first case, reactor temperature raised from $383 \mathrm{~K}$ to $387 \mathrm{~K}$ during the first 10 min of reaction whereas in the former no change in the reaction temperature was observed.

Catalyst Pt contents were chosen to cover different metal/acid balances due to its importance on hydrocracking catalysts performance. According to literature, a good balance can be obtained with $0.4-0.6 \% \mathrm{Pt}[10,23]$ and so Pt contents were representative of, in a simplistic way, low $(0.1 \% \mathrm{Pt})$, fair/good $(0.4 \% \mathrm{Pt})$ and high $(0.7 \% \mathrm{Pt})$ hydrogenating activity. Catalytic results are summarized on Table 3. The activity per catalyst weight, the activity per total number of available adsorption sites (defined as 
Bronsted and Lewis and Pt sites) and the turnover frequency (per metal site) $\mathrm{TOF}_{\mathrm{Pt}}$ at $\mathrm{t}=$ $1 \mathrm{~min}$, as well as the deactivation rate after $60 \mathrm{~min}$ of reaction were also determined. Figure 10 depicts the catalytic activity for Pt/HUSY and Pt/HBEA series as a function of reaction time and shows that deactivation occurs very quickly and, after 60 min of reaction, activity is very reduced. It is also possible to observe that for the same zeolite, the activity at 1 min increases with the Pt content in both catalysts series.

Figure 11a) depicts the $\mathrm{TOF}_{\mathrm{Pt}}$ for both catalyst series. For HUSY-based catalysts, $\mathrm{TOF}_{\mathrm{Pt}}$ for $0.7 \% \mathrm{Pt}$ is 1.7 times greater than that for $0.4 \%$ which is 2.3 times greater than that of $0.1 \%$. For HBEA-based catalysts, from $0.1 \% \mathrm{Pt}$ to $0.4 \% \mathrm{Pt}$, $\mathrm{TOF}_{\mathrm{Pt}}$ increased significantly whereas $0.4 \% \mathrm{Pt}$ is 1.2 times greater than that of $0.7 \% \mathrm{Pt}$. In a general way, $\mathrm{TOF}_{\mathrm{Pt}}$ is changing by 1.7 fold for HBEA series and 4.0 fold for HUSY series. Independently of the Pt content, the turnover frequency is always higher for HBEA-based catalysts than for HUSY ones. In summary, $\mathrm{TOF}_{\mathrm{Pt}}$ varies by 6-fold within these operating conditions, depending on both the metal content and the support.

Deactivation rates after 60 min of reaction range from 81 to $95 \%$ and are slightly higher for Pt/HUSY catalysts comparing to Pt/HBEA. The greatest difference occurred between the catalysts with lower Pt content (0.1 wt.\%). Differences between turnover frequencies of the two catalyst series are visibly higher than those observed at $t=1 \mathrm{~min}$ (see Figure 11), due to the HBEA-based catalysts lower deactivation rates. The deactivation rates are in line with the values published in literature for the deactivation of Pt/HUSY catalysts in similar reaction conditions: 84-95\% [33]. In the same study, deactivation has been shown to be caused by the blockage of micropores due to alkylation of toluene molecules by olefinic and dienic intermediates of their hydrogenation resulting in mostly $\mathrm{C}_{14}$ and $\mathrm{C}_{21}$ products. In our case, despite the similar BAS concentrations for both zeolites series (Figure 5), there are some differences in deactivation rates, which can be attributed to the different zeolite porous structures.

It is worthy to note that the discussion from this point on will be based in catalytic activities obtained at $\mathrm{t}=1 \mathrm{~min}$. Hypotheses made throughout cannot be applied for $\mathrm{t}=60$ min due to the changes in the catalyst occurring during reaction and subsequent deactivation process. 


\section{Discussion}

\subsection{Is toluene hydrogenation structure insensitive?}

The differences observed by comparing the turnover frequencies obtained for both zeolites as a function of Pt content (Figure 11) clearly shows that, within these operating conditions, toluene hydrogenation is sensitive to structure as, even for the same support, TOF $_{\mathrm{Pt}}$ is changing by a 1.7 fold for HBEA series and 4.0 fold for HUSY series.

The first idea of structure-insensivity of supported metal particles regarding benzene or toluene hydrogenation (using the definition established by Boudart [52], i.e. the catalyst activity could not be altered by the change of catalyst support) started to show some incongruence in the 1970's decade, as summarized by Gallezot [48]. More recent studies also confirm, in a general way, that TOF of Pt particles depends on the support characteristics, mainly on its acidity [34, 53-55]. On the other hand, Chupin et al. [33] proposed a linear correlation between activity and number of accessible Pt atoms for $\mathrm{Pt} / \mathrm{HFAU}$ catalyst series (which should be the result of constant $\mathrm{TOF}_{\mathrm{Pt}}$ ). However, according to the data reported in their work, there is an important increase in $\mathrm{TOF}_{\mathrm{Pt}}$ from 0.24 to 1.0 wt.\% Pt content (1333 vs. $2223 \mathrm{~h}^{-1}$ ), but when comparing 1.0 and $1.9 \%$ the $\mathrm{TOF}_{\mathrm{Pt}}$ values are similar and a slight decrease (0.85 fold) is observed for $2.5 \% \mathrm{Pt}$. On other studies, the observations of structure insensitivity were obtained at relatively high temperatures. In fact, benzene hydrogenation reaction is known to be less structure sensitive at high temperatures, as increasing temperatures disfavour adsorption and will thus tend to decrease the positive effects of a higher amount of adsorption sites [56]. Therefore, this work supports the mainstream tendency reported in literature contradicting the structure-insensitivity of toluene hydrogenation.

Several relevant studies published in literature [33, 34, 57] do not refer the possible influence of particle size on toluene hydrogenation and it is commonly accepted, in spite of some contradictory studies, the lack of relevance of particle size of Pt supported catalysts for one-ring aromatics hydrogenation [32]. Our results seem to support this hypothesis as, for instance, a same particle size can result in two very different TOF (0.4 and $0.7 \%$ Pt HUSY-based catalysts). 


\subsection{The role of acidity}

The importance of support characteristics, namely the acidity, on catalytic activity can be recognised by the changes on $\mathrm{TOF}_{\mathrm{Pt}}$ observed in a great range when comparing the two different zeolites (difference in textural properties, tortuosity, connectivity which impact the diffusion of the reactants are in the present study not considered since both zeolites HBEA and HUSY are classified as “large pore zeolites”). On the other hand, significant differences of $\mathrm{TOF}_{\mathrm{Pt}}$ measured for a Pt catalysts series supported on the same zeolite that, in a general way, keeps its properties irrespective of Pt load, can only be understood considering that support has an important role on reaction mechanism. This enhancement on one-ring aromatics hydrogenation activity has been related to acidity and it has been explained in literature by mainly two different mechanisms. The first one considers that strong interaction of BAS with metal particles may increase activity through improved particle electron deficiency or, in the limit, by creating "metal-proton adducts" [58]. The second one considers that additional sites for adsorption of the reactant that can be then hydrogenated by spilled over hydrogen $\left(\mathrm{H}_{\mathrm{sp}}\right)$ may also contribute to the hydrogenating activity [33, 34].

In our case of study, differences in metal-support interactions in the same catalyst series seem to be excluded according to the results from CO chemisorption: IR maxima of $\mathrm{Pt}^{0}$ CO band appear at ca. $2097+/-1 \mathrm{~cm}^{-1}$ for all catalysts (with similar average Pt particle size). Since $\mathrm{TOF}_{\mathrm{Pt}}$ changes significantly, an important contribution of $\mathrm{H}_{\mathrm{sp}}$ to the overall activity seems to be a hypothesis. As matter of fact, the enhanced activity due to support acidity has been commonly accepted to be due to the role of $\mathrm{H}_{\mathrm{sp}}$ for the last 20 years thanks mostly to the series of comprehensive studies performed by Vannice and coworkers on benzene and toluene hydrogenation [34,54]. They have shown that activity changed according to the support acidity $\left(\mathrm{SiO}_{2}-\mathrm{Al}_{2} \mathrm{O}_{3}>\mathrm{TiO}_{2}>\eta-\mathrm{Al}_{2} \mathrm{O}_{3}=\mathrm{SiO}_{2}\right)$ and this increase in $\mathrm{TOF}_{\mathrm{Pt}}$ has been attributed to the higher contribution of hydrogenation of adsorbed toluene on the acid sites by $\mathrm{H}_{\mathrm{sp}}$. To explain the higher rates obtained with acidic supports, Lin and Vannice [59] proposed a model that accurately fits the rate data and considers the total observed rate as the sum of two contributions: the metal surface $\left(\mathrm{TOF}_{\mathrm{Pt}}\right)$ and the support $\left(\mathrm{TOF}_{\mathrm{SP}}\right)$. $\mathrm{TOF}_{\mathrm{Pt}}$ was considered constant and equal to the one determined over non-acidic supports as $\mathrm{SiO}_{2}$ resulting in $\mathrm{TOF}_{\mathrm{SP}}$ contributions up to $80 \%$ of the overall activity [32]. The main criticism to this theory is the unfavourable 
thermodynamics of $\mathrm{H}_{\mathrm{sp}}$ diffusion on insulating materials like $\mathrm{SiO}_{2}, \mathrm{Al}_{2} \mathrm{O}_{3}$ and zeolites, only possible to overcome if the support has defects or is covered by a carbonaceous layer [60]. Very recently, J. Im et al. [61] addressed that critic and elucidated the role of $\mathrm{H}_{\mathrm{sp}}$ in benzene hydrogenation using platinum encapsulated in LTA zeolite that was therefore only accessible to $\mathrm{H}_{2}$. In that way, it was possible to study only the contribution to the activity of the hydrogenation of benzene on the acid sites and enhanced activity was observed. Moreover, using density functional theory (DFT) calculations, it was proposed that surface hydroxyls facilitate the surface migration of activated hydrogen.

In literature, it is possible to find some works [62] focused on the role of the different types and strength of acid sites. A first paper pointed out a correlation between the ratio of medium acid sites (adsorbing pyridine at $573 \mathrm{~K}$ ) to total acid sites and the activity in toluene hydrogenation of Pt/HAl-MCM-41 catalysts. The authors proposed that in catalysts with high percentage of medium acid sites, the probability to find Pt clusters surrounded by medium acid sites is enhanced and as a consequence the aromatic hydrogenation on medium acid sites could more efficiently take place than that on weak ones. However, total acidity ranged by 4 -fold and thus the fraction of medium to total acid sites may not give a correct idea about the concentration of medium acid sites available. Moreover, Pt dispersion was not measured. In a second paper [63], it was reported that at constant Pt load, the parent zeolite with more BAS (LAS were comparable) exhibited the highest hydrogenation activity. Catalysts with a broad range of Pt contents (0.05\% to $2 \%)$ supported on HUS-SSY zeolite were tested, but there is no information about Pt dispersion. In another paper [53], the authors showed that both LAS and BAS can be individually responsible for the enhancement of metal-supported catalysts on toluene hydrogenation by comparing Pt catalysts supported on either USSSY, HAl-MCM-41 or $\gamma-\mathrm{Al}_{2} \mathrm{O}_{3}$. In this study, activities seem to be correlated to the total or strong acidity of the supports, but without any specific proportion. Also in this case, the metal dispersion is not known and so a clear effect of the acidity cannot be extracted.

In summary, the lack of studies over metal catalysts based on highly acidic supports, as zeolites, leave us with many open questions regarding acidity role. For instance, is there any difference in activity between BAS and LAS and their roles in toluene 
hydrogenation? Both types of acid sites are able to adsorb toluene [53], but differences in adsorption/desorption may result in different reactivities of adsorbed toluene. As pyridine and toluene have similar kinetic diameters (0.54 [64] and $0.58 \mathrm{~nm}$ [65], respectively) no significant differences on accessibility are expected. On the other hand, strength can also play a role as weak interactions may activate toluene towards hydrogenation [60]. Moreover, pyridine is a stronger base (according to classical organic chemistry principles) and so weak acid sites that adsorb pyridine may not be able to adsorb toluene.

In our work, results indicate that HBEA-based catalysts have higher total acidity than HUSY and so the higher TOF ${ }_{\mathrm{Pt}}$ may be explained. Concerning the nature of acidity, BAS are roughly the same for both zeolites while the amount of LAS is 4 times larger for HBEA zeolite. Regarding medium acid sites to total acid sites ratio as proposed by Wang [62], the ratio is equal for HUSY and HBEA at $523 \mathrm{~K}(0.81)$, so the impact of this ratio in catalysts activity can be excluded.

\subsection{Activity per total adsorption sites}

As it has been evidenced, our results show the relevance of the support for the resulting activity per metal site. Thus, it seems adequate to study the possible correlations between Pt/zeolite catalyst properties and their influence on one-ring aromatics hydrogenation.

For the same reason that there is no conclusions in terms of some aspects of acidity (as strength and BAS vs. LAS), literature is scarce on clear properties-activity relationships: the small amount of studies published with zeolitic catalysts either compare a zeolite with a lower acidic support or did not present a comprehensive characterization of both metal and acid sites. From the point of view of the toluene hydrogenation mechanism proposed in literature, it comprises a dependence of the activity on the rate of $\mathrm{H}_{\mathrm{sp}}$ to the adsorption sites for toluene [34], i.e. hydrogenation of adsorbed toluene onto an acid site will depend on the ability of the metal site in its vicinity to supply enough hydrogen to hydrogenate the toluene molecule as soon as it has been adsorbed. Taking into account the important variation observed on turnover frequency (per metal site) as function of the number accessible Pt for Pt/HUSY and Pt/HBEA series (see Figure 12), this contribution seems to be also significant in our case. This hypothesis seems fairly 
plausible as, over $\mathrm{Pt} / \mathrm{SiO}_{2}-\mathrm{Al}_{2} \mathrm{O}_{3}$ catalysts, spillover route was found to contribute up to $80 \%$ to the overall rate reaction [32]. Therefore, if an important part of the catalyst activity can be attributed to the hydrogenation of adsorbed toluene on acid sites by $\mathrm{H}_{\mathrm{sp}}$, it seems that $\mathrm{TOF}_{\mathrm{Pt}}$ is rather inadequate to express the catalytic activity per site contributing to the hydrogenation rate. If toluene can be adsorbed onto both metal and acid sites (and, in the latter case, hydrogenated by $\mathrm{H}_{\mathrm{sp}}$ ), the determination of an activity per total number of available adsorbing sites could be a faithful measure for catalysts comprising highly acidic supports. All acid sites assessed by pyridine adsorption will be considered as adsorbing et aussi le Pt de surface non ?. Moreover, there is still another issue that must be considered regarding the catalyst property that can replicate more adequately its hydrogenating activity. Toluene can be adsorbed onto both metal and acid sites, but hydrogen dissociation is improbable on acid sites being only dissociatively adsorbed on the metal sites to be afterwards available to hydrogenate adsorbed toluene. Therefore, the accessible metal to total adsorbing sites ratio $\mathrm{n}_{\mathrm{Pt}} /\left(\mathrm{n}_{\mathrm{Pt}}+\mathrm{n}_{\mathrm{A}}\right)$ seems to be an appropriated choice.

Accordingly to this reasoning, Figure 13 depicts the evolution of the catalysts activity per total adsorbing sites as a function of the metal to total adsorbing sites ratio. Data from Chupin et al. study [33] were include because of the similarities in the catalysts and catalytic tests performed in their work compared to ours. In particular, toluene hydrogenation was carried out at the same temperature and $\mathrm{H}_{2}$ to toluene ratio and conversions at initial time were low in both studies. Total acidity was also determined for each catalyst by pyridine chemisorption followed by FTIR and results were normalized with extinction coefficients similar to the ones used in our work. The quantification of accessible $\mathrm{Pt}$ was also determined by $\mathrm{H}_{2}-\mathrm{O}_{2}$ titration verified by $\mathrm{CO}$ chemisorption. Concerning the results, in all the three catalyst series, the activity per total adsorbing sites increases steadily with $\mathrm{n}_{\mathrm{Pt}} /\left(\mathrm{n}_{\mathrm{Pt}}+\mathrm{n}_{\mathrm{A}}\right)$. This fact goes in line with a great contribution of spillover mechanism to hydrogenation activity. It means that for a given zeolite, with constant acid sites concentration, the increase of accessible Pt atoms leads to an increase on the amount of $\mathrm{H}_{\mathrm{sp}}$ available for the same amount of acid sites and so the catalytic activity per acid site should increase along with that of metal sites. So, a higher activity per total adsorbing site and even an higher $\mathrm{TOF}_{\mathrm{Pt}}$ calculated as it is. 
This reasoning comprises an important hypothesis: activity of acid sites will only increase if there is any margin to, i.e. there were sites being supplied with a lower rate of $\mathrm{H}_{\mathrm{sp}}$ than that required for their maximum activity. This maximum of activity cannot be observed for any of the catalysts series. In this way, this type of analysis takes into account the role of acidity in toluene hydrogenation and, even if it is somehow simplistic, can be used effectively as measure of hydrogenating activity.

\subsection{Influence of the zeolite on the hydrogenating activity}

Comparisons based on the activity per total number of adsorbing sites $\left(\mathrm{n}_{\mathrm{Pt}}+\mathrm{n}_{\mathrm{A}}\right)$ as function of $n_{P t} /\left(n_{P t}+n_{A}\right)$ enable to withdraw the effect of the total acidity on the activity. In this way, one could say that all catalysts should fit the same tendency of activity. Observing Figure 13, all Pt/HUSY catalysts (both from our work and Chupin [33]) fit the same tendency, but Pt/HBEA catalysts presents higher activities. Comparing both series, HBEA-based catalysts with the lowest $n_{P t} /\left(n_{P t}+n_{A}\right)$ have higher activity per total adsorbing sites than Pt/HUSY catalysts with a higher $\mathrm{n}_{\mathrm{Pt}} /\left(\mathrm{n}_{\mathrm{Pt}}+\mathrm{n}_{\mathrm{A}}\right)$ and this difference seems to increase even more with $\mathrm{n}_{\mathrm{Pt}} /\left(\mathrm{n}_{\mathrm{Pt}}+\mathrm{n}_{\mathrm{A}}\right)$ augmentation (in our working range). The fact that two different series of HUSY-based catalysts have similar evolutions of activity per total adsorbing sites as function of $n_{P t} /\left(n_{P t}+n_{A}\right)$ and that HBEA-based catalysts have a different evolution seems to point out the importance of the zeolite on the catalytic activity observed per total adsorbing site.

As pointed out earlier, the type of acid sites may also matter in terms of its importance to catalytic activity. From our results, it seems correct to presume that both BAS and LAS can activate toluene that will be hydrogenated by $\mathrm{H}_{\mathrm{sp}}$ species. Nevertheless, the comparison based on pyridine adsorption results is valid only if toluene adsorption follows a similar BAS to LAS ration. Regarding total acidity, HBEA-based catalyst have around $63 \%$ of LAS whereas HUSY based have around 30\% (our work) or 20\% (Chupin work). Therefore, the fact that HBEA-based catalysts have a higher activity per acid site than HUSY one may indicate that the assumption that BAS and LAS contribute equivalently to the catalytic activity is not fully correct. In that case, LAS would have a higher contribution which, till now, has not been an object of discussion in literature. Concerning textural properties, Wang and co-workers found a similar conversion in hydrogenation of toluene by comparing Pt catalysts supported on both 
US-SSY and $\gamma-\mathrm{Al}_{2} \mathrm{O}_{3}$ with similar total acidity [53]. The differences in the porous volume as well as in the external surface between HBEA and HUSY zeolites were ruled out as a key factor to distinguish catalytic activities in our case of study.

Finally, it will be important to take into account that metal-acid sites distance can play a crucial role on the activity for catalysts in which acid sites activity did not yet attained a maximal activity (as in this case of study) due to the low supply of these sites by $\mathrm{H}_{\mathrm{sp}}$ or even because some sites are not supplied by any $\mathrm{H}_{\mathrm{sp}}$. A smaller pathway between $\mathrm{Pt}$ clusters and acid sites will increase the rate of $\mathrm{H}_{\mathrm{sp}}$ reaching the acid sites. IR spectra in the $\mathrm{OH}$ region of HBEA-based catalysts showed that the contribution at $3606 \mathrm{~cm}^{-1}$ related with BAS and the contribution at $3665 \mathrm{~cm}^{-1}$ assigned to $\mathrm{OH}$ groups on EFAL species were shifted to high wavenumbers after Pt introduction. Additionally, the intensity of $3606 \mathrm{~cm}^{-1}$ was reduced by $45 \%$ which could not be a unique consequence of the $\mathrm{Pt}^{2+}$ presence as the lost in BAS was only $10 \%$. It was proposed that these marked spectral features indicate the proximity of $\mathrm{Pt}$ particles and $\mathrm{OH}$ groups, without significant changes on the metal-support interactions according to the similar IR maxima of $\mathrm{Pt}^{0}-\mathrm{CO}$ contribution for all catalysts. On the contrary, IR spectra in the $\mathrm{OH}$ region of HUSY-based catalysts show no particular difference to the parent zeolite and neither among the impregnated samples. Therefore, the proximity between Pt clusters and $\mathrm{OH}$ groups in HBEA-based catalysts may explain their higher activity for similar $\mathrm{n}_{\mathrm{Pt}} /\left(\mathrm{n}_{\mathrm{Pt}}+\mathrm{n}_{\mathrm{A}}\right)$ comparing to HUSY-based catalysts.

In this way, the hydrogenating activity of a Pt/zeolite catalyst is a function of the total acidity, but not uniquely. The proximity between Pt clusters and acid sites may improve $\mathrm{H}_{\mathrm{sp}}$ diffusion efficiency and LAS may also have larger role than that resulting from pyridine adsorption.

\section{Conclusion}

Toluene hydrogenation was studied over catalysts based on Pt supported on large pore zeolites (HUSHY and HBEA) containing different metal/acid sites ratio.

Parent zeolites and Pt catalysts were characterized in terms of acidity by pyridine desorption, which has a similar kinetic diameter compared to toluene, followed by in situ FTIR. Metal dispersion determined by $\mathrm{H}_{2}-\mathrm{O}_{2}$ titration was found to be linearly 
correlated with the intensity of $\mathrm{Pt}^{0}$-CO band determined by in situ FTIR, which enable to cross-check metal dispersion determined by each one of the techniques.

Toluene hydrogenation seems to be structure-sensitive as, even for the same support, $\mathrm{TOF}_{\mathrm{Pt}}$ are increasing by a 1.7 fold for HBEA series and 4.0 fold for HUSY series with increasing amount of accessible metal. The enhanced activity was proposed to be due to the contribution to the overall activity of the hydrogenation of adsorbed toluene via hydrogen spillover. The absence of dissimilarities in the electronic properties of $\mathrm{Pt}^{0}$ clusters of similar average particle size observed by CO chemisorption followed by FTIR, exclude the hypothesis, as suggest in some literature, of enhanced activity as consequence of different strong metal-support interactions.

To compare catalysts with different supports, $\mathrm{TOF}_{\mathrm{Pt}}$ was proposed to be rather inadequate, as it does not take into account the role of acidity. Instead, an activity per total number of adsorbing sites was suggested and it was observed that the activity per total adsorbing sites increases steadily with $\mathrm{n}_{\mathrm{Pt}} /\left(\mathrm{n}_{\mathrm{Pt}}+\mathrm{n}_{\mathrm{A}}\right)$ which represents the ratio of hydrogenating to adsorbing sites. This is in line with the fact that an increase of the accessible Pt atoms will result in an increase on the amount of spilled over hydrogen available for the acid sites and so the acid sites activity should increase, until the maximum activity will be reached.

Pt/HUSY catalysts seem to fit a similar tendency in the activity per total adsorbing sites as $n_{P_{t}} /\left(n_{P_{t}}+n_{A}\right)$ augments. On the other hand, the HBEA-based catalysts have higher activity per total adsorbing sites than Pt/HUSY catalysts for the same $n_{P t} /\left(n_{P t}+n_{A}\right)$, in our working range. These two facts point out to the importance of zeolite to the activity observed per acid site and that it does not depend uniquely of the total acidity. Metal particles in the vicinity of acid sites were detected by shift in $\mathrm{OH}$ groups contribution of HBEA after Pt introduction. It was suggested that proximity between Pt clusters and acid sites may be a key difference as acid sites activity depends mostly in the rate of $\mathrm{H}_{\mathrm{sp}}$ being supplied to them.

In summary, for metals supported in acid zeolites with no shape selectivity it seems rather clear that toluene hydrogenation is a structure sensitive reaction and the catalytic activity depends not only on the accessible metal, but also on the total acidity for a given zeolite. This significant dependence on the zeolite total acidity is due to the vital 
contribution of hydrogenation of adsorbed toluene via $\mathrm{H}_{\mathrm{sp}}$ to the overall activity. Nevertheless, total acidity is not the only parameter to take into account in zeolites. The improved activity of Pt/HBEA series compared to Pt/HUSY is proposed to be due to the proximity between Pt clusters and acid sites detected by IR spectra in the $\mathrm{OH}$ region or/and to a larger role of Lewis acid sites in the mechanism compared to pyridine adsorption results. These results reinforce the importance of model reactions, like toluene hydrogenation, as a closest perspective to the reaction in study itself which may help to explain phenomena that cannot be seen by characterization techniques. This information may also be very helpful to the design of new aromatic hydrogenation catalysts based on noble metal deposited on large pore zeolites.

\section{Acknowledgments}

Authors would like to thank to L. Blanchon for her dedicated technical support to this study as well as E. Soyer for all the work performed on FTIR characterization techniques. Pedro S. F. Mendes would like to thank to Fundação para a Ciência e a Tecnologia for his PhD grant (SFRH/BD/87927/2012).

\section{References}

[1] T. Degnan, Jr., Applications of zeolites in petroleum refining, Top. Catal., 13 (2000) 349-356.

[2] V.M. Akhmedov, S.H. Al-Khowaiter, Recent advances and future aspects in the selective isomerization of high n-alkanes, Catal. Rev., 49 (2007) 33-139.

[3] L.B. McCusker, C. Baerlocher, Zeolite structures, in: J. Cejka, H. VanBekkum (Eds.) Zeolites and Ordered Mesoporous Materials: Progress and Prospects, Elsevier Science Bv, Amsterdam, 2005, pp. 41-64.

[4] H. Abrevaya, Unique Aspects of Mechanisms and Requirements for Zeolite Catalysis in Refining and Petrochemicals, Zeolites in Industrial Separation and Catalysis, Wiley-VCH Verlag GmbH \& Co. KGaA, 2010, pp. 403-478.

[5] C. Bouchy, G. Hastoy, E. Guillon, J.A. Martens, Fischer-Tropsch Waxes Upgrading via Hydrocracking and Selective Hydroisomerization, Oil Gas Sci. Technol., 64 (2009) 91-112. 
[6] Q.H. Zhang, J.C. Kang, Y. Wang, Development of Novel Catalysts for FischerTropsch Synthesis: Tuning the Product Selectivity, ChemCatChem., 2 (2010) 10301058.

[7] Q.H. Zhang, W.P. Deng, Y. Wang, Recent advances in understanding the key catalyst factors for Fischer-Tropsch synthesis, J. Energy Chem., 22 (2013) 27-38.

[8] E.F. Iliopoulou, E. Heracleous, A. Delimitis, A.A. Lappas, Producing high quality biofuels: Pt-based hydroisomerization catalysts evaluated using BtL-naphtha surrogates, Applied Catalysis B: Environmental, 2013.

[9] F. Bertoncini, A. Bonduelle-Skrzypczak, J. Francis, E. Guillon, Hydrocraking, in: H. Toulhoat, P. Raybaud (Eds.) Catalysis by Transition Metal Sulphides, Editions Technip, Paris, 2013, pp. 632-655.

[10] H. Deldari, Suitable catalysts for hydroisomerization of long-chain normal paraffins, Appl. Catal., A, 293 (2005) 1-10.

[11] K.C. Park, S.K. Ihm, Comparison of Pt/zeolite catalysts for n-hexadecane hydroisomerization, Appl. Catal., A, 203 (2000) 201-209.

[12] A. Gutiérrez, J.M. Arandes, P. Castaño, M. Olazar, J. Bilbao, Preliminary studies on fuel production through LCO hydrocracking on noble-metal supported catalysts, Fuel, 94 (2012) 504-515.

[13] J.A. Martens, M. Tielen, P.A. Jacobs, Relation Between Paraffin Isomerisation Capability and Pore Architecture of Large-Pore Bifunctional Zeolites, in: H.G. Karge, J. Weitkamp (Eds.) Stud. Surf. Sci. Catal., Elsevier1989, pp. 49-60.

[14] W.M. Zhang, P.G. Smirniotis, Effect of zeolite structure and acidity on the product selectivity and reaction mechanism for n-octane hydroisomerization and hydrocracking, J. Catal., 182 (1999) 400-416.

[15] M. Steijns, G. Froment, P. Jacobs, J. Uytterhoeven, J. Weitkamp, Hydroisomerization and Hydrocracking. 2. Product Distributions from $n$-Decane and $n$ Dodecane, Ind. Eng. Chem. Prod. Res. Dev., 20 (1981) 654-660.

[16] J.A. Martens, P.A. Jacobs, J. Weitkamp, Attempts to rationalize the distribution of hydrocracked products. 1. Qualitative description of the primary hydrocracking modes of long-chain paraffins in open zeolites, Appl. Catal., 20 (1986) 239-281.

[17] J.A. Martens, P.A. Jacobs, J. Weitkamp, Attemps to rationalize the distribution of hydrocracked products. 2. Relative rates of primary hydrocraking modes of long-chain paraffins in open zeolites, Appl. Catal., 20 (1986) 283-303.

[18] F. Alvarez, G. Giannetto, M. Guisnet, G. Perot, Hydroisomerization and hydrocracking of n-Alkanes. 2. n-Heptane transformation on a Pt-dealuminated Y zeolite - comparison with a Pt-Y zeolite, Appl. Catal., 34 (1987) 353-365. 
[19] F. Alvarez, F.R. Ribeiro, G. Giannetto, F. Chevalier, G. Perot, M. Guisnet, Hydroisomerization and Hydrocracking of Alkanes. 5. Hydroisomerization and Hydrocracking of N-Hexane and N-Heptane on PtHY Catalysts. Effect of the Distribution of Metallic and Acid Sites, in: P.A. Jacobs, R.A.v. Santen (Eds.) Stud. Surf. Sci. Catal., Elsevier, 1989, pp. 1339-1348.

[20] F. Alvarez, F.R. Ribeiro, G. Perot, C. Thomazeau, M. Guisnet, Hydroisomerization and hydrocracking of alkanes - Influence of the balance between acid and hydrogenating functions on the transformation of n-decane on PtHY catalysts, J. Catal., 162 (1996) 179-189.

[21] J. Weitkamp, Catalytic Hydrocracking-Mechanisms and Versatility of the Process, ChemCatChem, 4 (2012) 292-306.

[22] M. Guisnet, “Ideal” bifunctional catalysis over Pt-acid zeolites, Catal. Today, 218219 (2013) 123-134.

[23] J. Hagen, Industrial Catalysis: A Practical Approach, Wiley, 2006, p. 254.

[24] P.B. Weisz, Polyfunctional Heterogeneous Catalysis, in: D.D. Eley, P.W. Selwood, P.B. Weisz, A.A. Balandin, J.H.D. Boer, P.J. Debye, P.H. Emmett, J. Horiuti, W. Jost, G. Natta, E.K. Rideal, H.S. Taylor (Eds.) Advances in Catalysis, Academic Press, 1962, pp. 137-190.

[25] H.L. Coonradt, W.E. Garwood, Mechanism of hydrocracking - reactions of paraffins + olefins, Industrial \& Engineering Chemistry Process Design and Development, 3 (1964) p. 38.

[26] N. Batalha, L. Pinard, Y. Pouilloux, M. Guisnet, Bifunctional Hydrogenating/Acid Catalysis: Quantification of the Intimacy Criterion, Catal. Lett., 143 (2013) 587-591.

[27] N. Batalha, L. Pinard, C. Bouchy, E. Guillon, M. Guisnet, n-Hexadecane hydroisomerization over Pt-HBEA catalysts. Quantification and effect of the intimacy between metal and protonic sites, J. Catal., 307 (2013) 122-131.

[28] C.H. Bartholemew, $\mathrm{H}_{2}$ adsorption on supported noble metals and its use in determining metal dispersion, in: J.J. Spivey, S.K. Agarwal (Eds.) Catalysis: Volume 11, The Royal Society of Chemistry, 1994, pp. 93-126.

[29] K.I. Hadjiivanov, G.N. Vayssilov, Characterization of oxide surfaces and zeolites by carbon monoxide as an IR probe molecule, Advances in Catalysis, Academic Press, 2002, pp. 307-511.

[30] B. Hunger, M.V. Vonszombathely, J. Hoffmann, P. Brauer, Characterization of the acidic properties of zeolites by means of temperature-programmed desorption (TPD) of ammonia - calculation of distribution-functions of the desorption energy, J. Therm. Anal., 44 (1995) 293-303. 
[31] C.A. Emeis, Determination of Integrated Molar Extinction Coefficients for Infrared Absorption Bands of Pyridine Adsorbed on Solid Acid Catalysts, J. Catal., 141 (1993) 347-354.

[32] G.C. Bond, Hydrogenation of the Aromatic Ring, in: G.C. Bond (Ed.) MetalCatalysed Reactions of Hydrocarbons, Springer US, 2005, pp. 437-471.

[33] J. Chupin, N.S. Gnep, S. Lacombe, M. Guisnet, Influence of the metal and of the support on the activity and stability of bifunctional catalysts for toluene hydrogenation, Appl. Catal., A, 206 (2001) 43-56.

[34] S.D. Lin, M.A. Vannice, Toluene Hydrogenation Over Supported Platinum Catalysts, in: L. Guczi, F. Solymosi, P. Tétényi (Eds.) Stud. Surf. Sci. Catal., Elsevier, 1993, pp. 861-874.

[35] P. Chou, M.A. Vannice, Benzene hydrogenation over supported and unsupported palladium: I. Kinetic behavior, J. Catal., 107 (1987) 129-139.

[36] J.P. Marques, I. Gener, P. Ayrault, J.M. Lopes, F.R. Ribeiro, M. Guisnet, Semiquantitative estimation by IR of framework, extraframework and defect Al species of HBEA zeolites, Chem. Comm., (2004) 2290-2291.

[37] G. Leofanti, M. Padovan, G. Tozzola, B. Venturelli, Surface area and pore texture of catalysts, Catal. Today, 41 (1998) 207-219.

[38] J. Prasad, K.R. Murthy, P.G. Menon, Stoichiometry of Hydrogen-Oxygen Titrations on Supported Platinum Catalysts, J. Catal., 52 (1978) 515-520.

[39] M. Fadoni, L. Lucarelli, Temperature programmed desorption, reduction, oxidation and flow chemisorption for the characterisation of heterogeneous catalysts. Theoretical aspects, instrumentation and applications, in: A. Dąbrowski (Ed.) Stud. Surf. Sci. Catal., Elsevier, 1999, pp. 177-225.

[40] G. Harvey, G. Binder, R. Prins, The contribution of the external surface to the catalytic activity of zeolite beta, in: H. K. Beyer, H. G. Karge, I. Kiricsi, J. B. Nagy (Eds.) Catalysis by Microporous Materials, Elsevier, Amsterdam, 1995.

[41] P.J. Kunkeler, B.J. Zuurdeeg, J.C. van der Waal, J.A. van Bokhoven, D.C. Koningsberger, $\mathrm{H}$. van Bekkum, Zeolite Beta: The relationship between calcination procedure, aluminum configuration, and Lewis acidity, J. Catal., 180 (1998) 234-244.

[42] S.B. Liu, J.F. Wu, L.J. Ma, T.C. Tsai, I. Wang, On the Thermal-Stability of Zeolite Beta, J. Catal., 132 (1991) 432-439.

[43] O. Cairon, T. Chevreau, J.-C. Lavalley, Bronsted acidity of extraframework debris in steamed Y zeolites from the FTIR study of CO adsorption J. Chem. Soc., Faraday Trans., 94 (1998) 3039-3047. 
[44] M. Maache, A. Janin, J.C. Lavalley, J.F. Joly, E. Benazzi, Acidity of zeolites Beta dealuminated by acid leaching: An FTIR study using different probe molecules (pyridine, carbon monoxide), Zeolites, 13 (1993) 419-426.

[45] M. Guisnet, P. Ayrault, C. Coutanceau, M. Fernanda Alvarez, J. Datka, Acid properties of dealuminated beta zeolites studied by IR spectroscopy, J. Chem. Soc., Faraday Trans., 93 (1997) 1661-1665.

[46] I. Kiricsi, C. Flego, G. Pazzuconi, W.O. Parker, Jr., R. Millini, C. Perego, G. Bellussi, Progress toward Understanding Zeolite .beta. Acidity: An IR and 27Al NMR Spectroscopic Study, The Journal of Physical Chemistry, 98 (1994) 4627-4634.

[47] J.A. Lercher, C. Gründling, G. Eder-Mirth, Infrared studies of the surface acidity of oxides and zeolites using adsorbed probe molecules, Catal. Today, 27 (1996) 353-376.

[48] P. Gallezot, State and Catalytic Properties of Platinum and Palladium in FaujasiteType Zeolites, Catal. Rev., 20 (1979) 121-154.

[49] S. Bathia, Zeolites Catalysts: Principles and Applications, CRC Press, 1989, pp. 116-122.

[50] A.Y. Stakheev, L.M. Kustov, Effects of the support on the morphology and electronic properties of supported metal clusters: modern concepts and progress in 1990s, Appl. Catal., A, 188 (1999) 3-35.

[51] J.N. Kondo, E. Yoda, H. Ishikawa, F. Wakabayashi, K. Domen, Acid Property of Silanol Groups on Zeolites Assessed by Reaction Probe IR Study, J. Catal., 191 (2000) 275-281.

[52] M. Boudart, A. Aldag, J.E. Benson, N.A. Dougharty, C. Girvin Harkins, On the specific activity of platinum catalysts, J. Catal., 6 (1966) 92-99.

[53] J. Wang, H.Y. Chen, Q.Z. Li, Influence of the Bronsted and Lewis acid sites in platinum/solid acid catalysts on the hydrogenation of benzene and toluene, React. Kinet. Catal. Lett., 69 (2000) 277-284.

[54] S.D. Lin, M.A. Vannice, Hydrogenation of Aromatic Hydrocarbons over Supported Pt Catalysts. II. Toluene Hydrogenation, J. Catal., 143 (1993) 554-562.

[55] P. Reyes, M. Oportus, G. Pecchi, R. Frety, B. Moraweck, Influence of the nature of the platinum precursor on the surface properties and catalytic activity of aluminasupported catalysts, Catal Lett., 37 (1996) 193-197.

[56] J. Cosyns, The Hydrogenation of Hydrocarbons, in: B. Imelik, G.A. Martin, A.J. Renouprez (Eds.) Catalyse par les Métaux, CNRS, 1984, pp. 371-400.

[57] D. Poondi, M. Albert Vannice, Competitive Hydrogenation of Benzene and Toluene on Palladium and Platinum Catalysts, J. Catal., 161 (1996) 742-751. 
[58] C.P. Nicolaides, M.S. Scurrell, Chapter 6: Catalytic Properties of Metal Clustersinzeolites, in: S. Kaliaguine (Ed.) Stud. Surf. Sci. Catal., Elsevier, 1988, pp. 319-379.

[59] S.D. Lin, M.A. Vannice, Hydrogenation of Aromatic Hydrocarbons over Supported Pt Catalysts .III. Reaction Models for Metal Surfaces and Acidic Sites on Oxide Supports, J. Catal., 143 (1993) 563-572.

[60] R. Prins, Hydrogen Spillover. Facts and Fiction, Chem. Rev., 112 (2012) 27142738.

[61] J. Im, H. Shin, H. Jang, H. Kim, M. Choi, Maximizing the catalytic function of hydrogen spillover in platinum-encapsulated aluminosilicates with controlled nanostructures, Nat. Commun., 5 (2014).

[62] J. Wang, L.M. Huang, H.Y. Chen, Q.Z. Li, Acid function of Al-MCM-41 supported platinum catalysts in hydrogenation of benzene, toluene and o-xylene, Catal. Lett., 55 (1998) 157-163.

[63] J. Wang, Q. Li, J. Yao, The effect of metal-acid balance in Pt-loading dealuminated Y zeolite catalysts on the hydrogenation of benzene, Appl. Catal., A, 184 (1999) 181-188.

[64] J.A. Lercher, A. Jentys, Chapter 13 Infrared and raman spectroscopy for characterizing zeolites, in: H.v.B.A.C. Jiř́i Čejka, S. Ferdi (Eds.) Stud. Surf. Sci. Catal., Elsevier, 2007, pp. 435-476.

[65] A. Réguer, S. Sochard, C. Hort, V. Platel, Measurement and modelling of adsorption equilibrium, adsorption kinetics and breakthrough curve of toluene at very low concentrations on to activated carbon, Environ. Technol., 32 (2011) 757-766. 


\section{Figure Captions}

Figure 1. FTIR spectra in the hydroxyl region of HUSY and Pt/HUSY catalysts after activation at $723 \mathrm{~K}$ under secondary vacuum. From top to bottom spectra: 0.7, 0.4, 0.1 and 0.0 wt.\% Pt/HUSY

Figure 2. FTIR spectra in a) the hydroxyl region and b) detail of $\mathrm{Si}(\mathrm{OH}) \mathrm{Al}$ contribution of HBEA and Pt/HBEA catalysts after activation at $723 \mathrm{~K}$ under secondary vacuum. From top to bottom spectra: 0.7, 0.4, 0.1 and $0.0 \mathrm{wt}$.\%Pt/HBEA. In inset, the intensities have been normalized in order to focus on the frequency shift observed as a function of Pt content.

Figure 3. Evolutions of the positions and intensities of the $\mathrm{VOH}$ of SiOHAl BAS sites (at ca. $3606 \mathrm{~cm}^{-1}$ for HBEA) and AlOH EFAL species (at ca. $3662 \mathrm{~cm}^{-1}$ for HBEA); left and right panels respectively. The semi-quantification has been done after normalization with the contribution due to silanol groups expected to be poorly affected by Pt atoms.

Figure 4. Evolutions of the positions and areas $\left(3650-3550 \mathrm{~cm}^{-1}\right)$ of the hydroxyl groups within the supercages and small cavities (at 3629 and $3566 \mathrm{~cm}^{-1}$ ); left and right panels respectively. The semi-quantification has been done after normalization with the contribution due to silanol groups expected to be poorly affected by Pt atoms.

Figure 5. Concentrations (in $\mu \mathrm{mol} / \mathrm{g}$ ) of BAS and LAS sites on a) HUSY zeolite, b) 0.7Pt/HUSY, c) HBEA and d) 0.7Pt/HBEA samples measured by pyridine thermodesorption followed by FTIR.

Figure 6. IR spectra of pre-reduced HUSY and Pt/HUSY catalysts at CO saturation. From top to bottom spectrum: 0.7, 0.4, 0.1 and 0.0 wt.\% Pt.

Figure 7. IR spectra of pre-reduced HBEA and Pt/HBEA catalysts at CO saturation. From top to bottom spectrum: 0.7, 0.4, 0.1 and 0.0 wt.\% Pt.

Figure 8. Number of $\mathrm{Pt}$ surface atoms measured by $\mathrm{H}_{2}-\mathrm{O}_{2}$ titration plotted as a function of the intensity of the $v \mathrm{CO}$ at $2097 \mathrm{~cm}^{-1}$ from $\mathrm{Pt}^{\circ} \mathrm{CO}$ species for both series: HUSY and HBEA. 
Figure 9. STEM micrograph for $0.1 \% \mathrm{Pt} / \mathrm{HBEA}$ and TEM micrograph for $0.7 \% \mathrm{Pt} / \mathrm{HUSY}$.

Figure 10. Activity as function of time-on-stream for a) Pt/HUSY and b) Pt/HBEA series in toluene hydrogenation.

Figure 11. Turnover frequencies (per metal site) at a) $t=1 \min$ and $b$ ) $t=60 \min$ as function of $\mathrm{Pt}$ content for Pt/HBEA $(\diamond)$ and Pt/HUSY $(\square)$ series in toluene hydrogenation.

Figure 11. Turnover frequency (per metal site) at $\mathrm{t}=1 \mathrm{~min}$ as function of the number accessible Pt for Pt/HBEA ( $\diamond$ ) and Pt/HUSY ( $\square$ ) series in toluene hydrogenation.

Figure 13. Activity per total adsorbing site as function of $n \mathrm{Pt} /(\mathrm{nPt}+\mathrm{nA})$ for $\mathrm{Pt} / \mathrm{HBEA}$ $(\diamond)$ and Pt/HUSY ( $\square$ ) series in toluene hydrogenation. A series of Pt/HUSY catalysts (O) from Chupin et al. [33] were also included. 


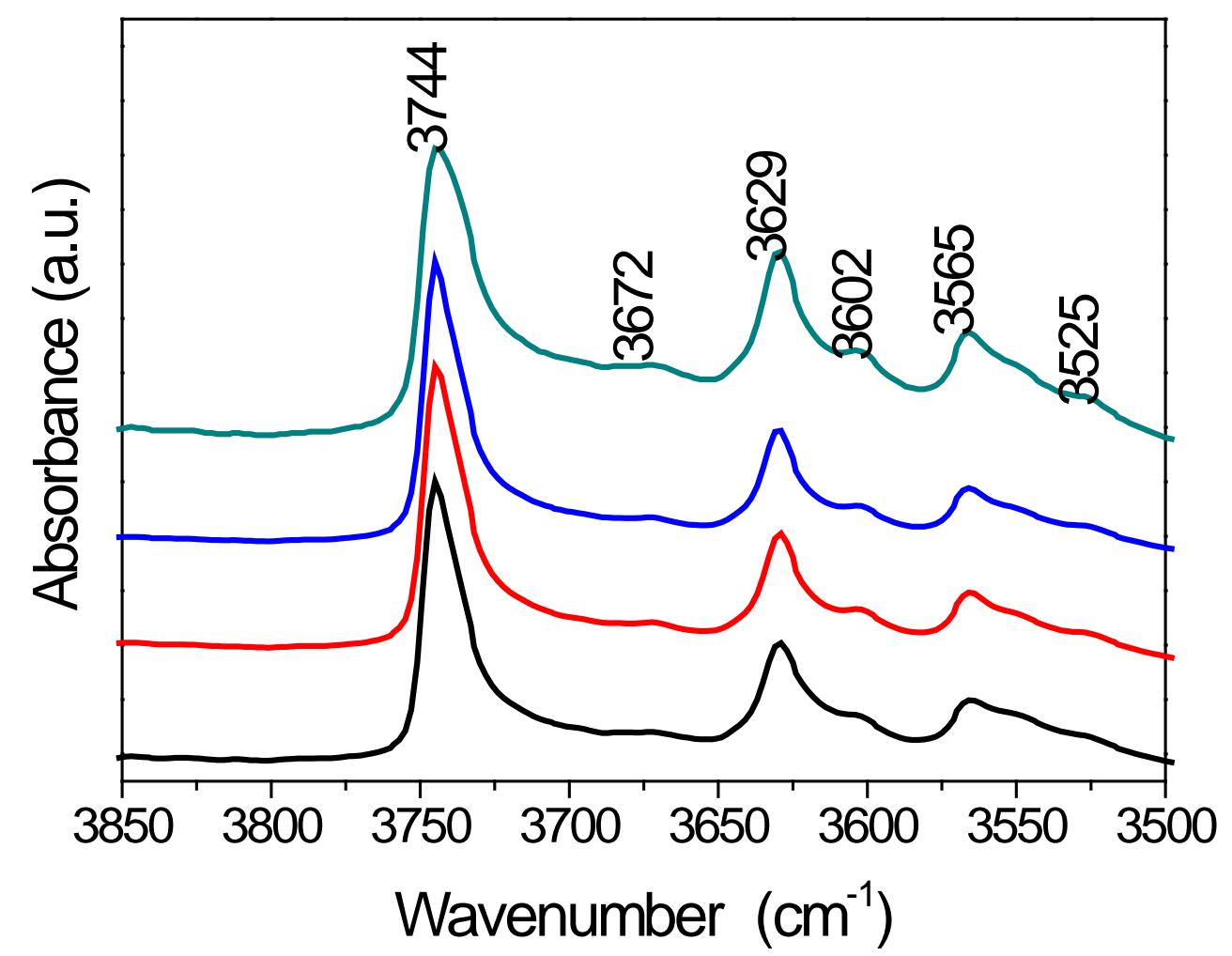

Figure 1. FTIR spectra in the hydroxyl region of HUSY and Pt/HUSY catalysts after activation at $723 \mathrm{~K}$ under secondary vacuum. From top to bottom spectra: $0.7,0.4,0.1$ and $0.0 \mathrm{wt} . \% \mathrm{Pt} / \mathrm{HUSY}$. 


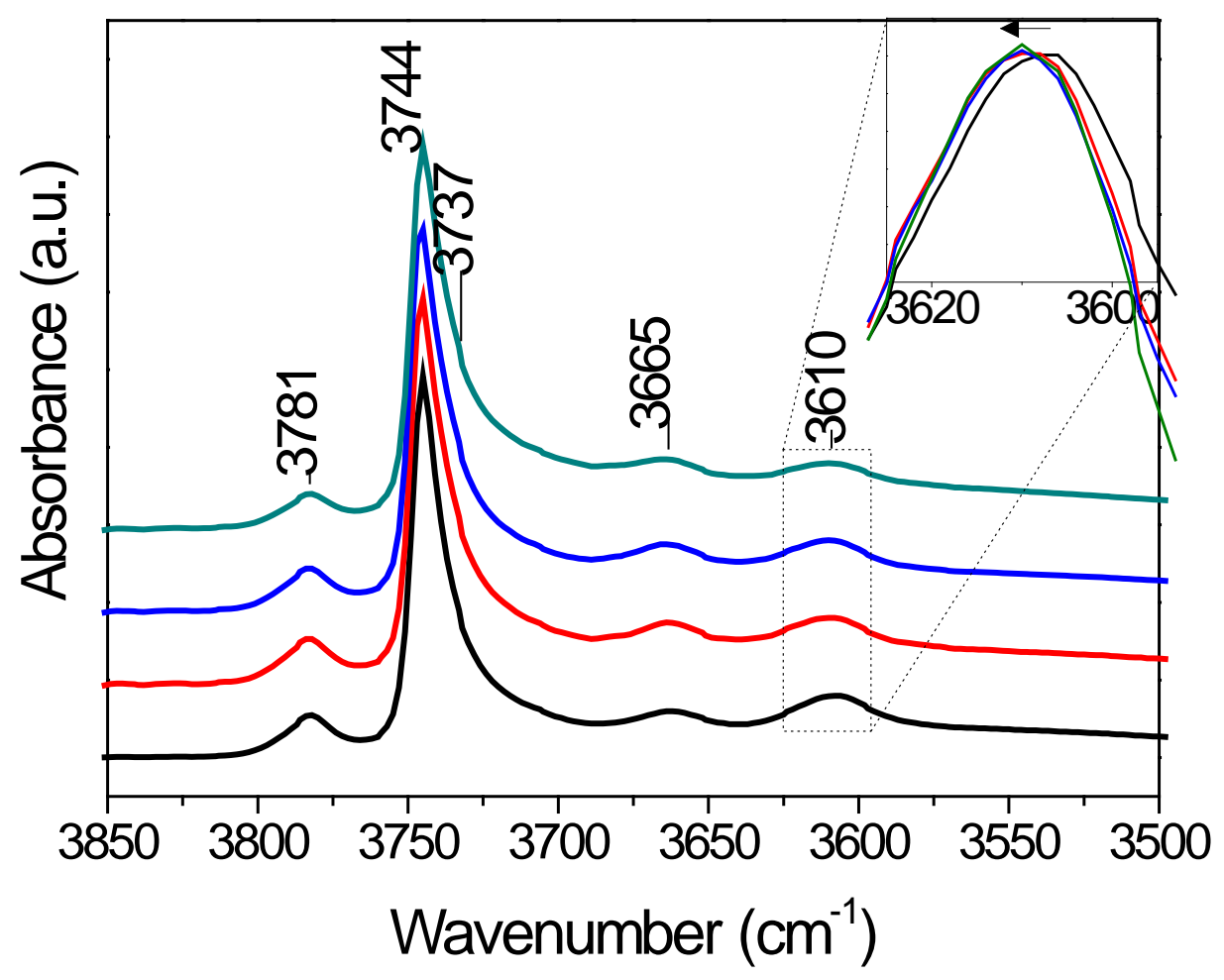

Figure 2. FTIR spectra in a) the hydroxyl region and b) detail of $\mathrm{Si}(\mathrm{OH}) \mathrm{Al}$ contribution of HBEA and Pt/HBEA catalysts after activation at $723 \mathrm{~K}$ under secondary vacuum. From top to bottom spectra: $0.7,0.4,0.1$ and $0.0 \mathrm{wt} . \% \mathrm{Pt} / \mathrm{HBEA}$. In inset, the intensities have been normalized in order to focus on the frequency shift observed as a function of Pt content. 

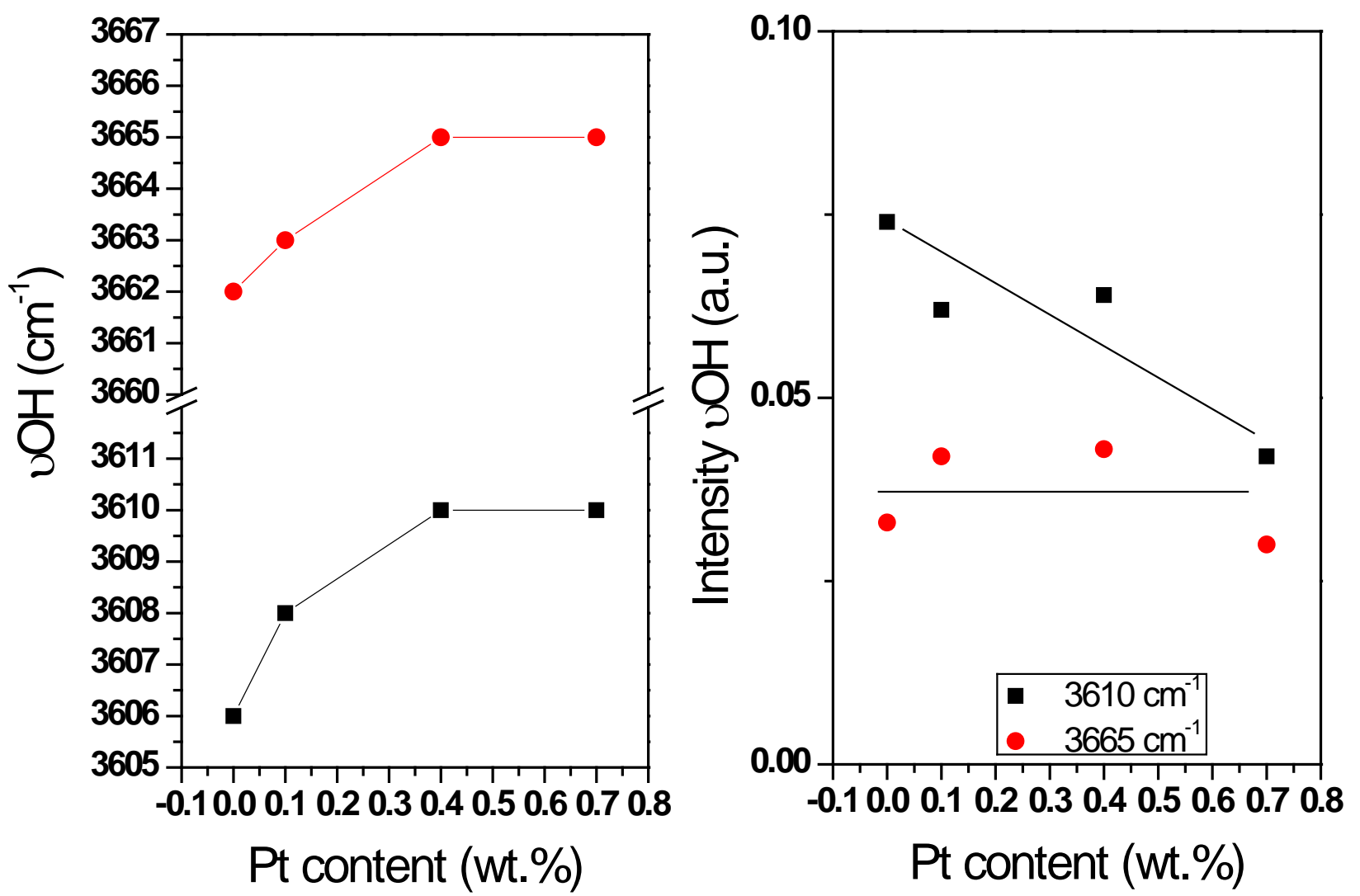

Figure 3. Evolutions of the positions and intensities of the vOH of SiOHAl BAS sites (at ca. $3606 \mathrm{~cm}^{-1}$ for HBEA) and AlOH EFAL species (at ca. $3662 \mathrm{~cm}^{-1}$ for HBEA); left and right panels respectively. The semi-quantification has been done after normalization with the contribution due to silanol groups expected to be poorly affected by Pt atoms. 

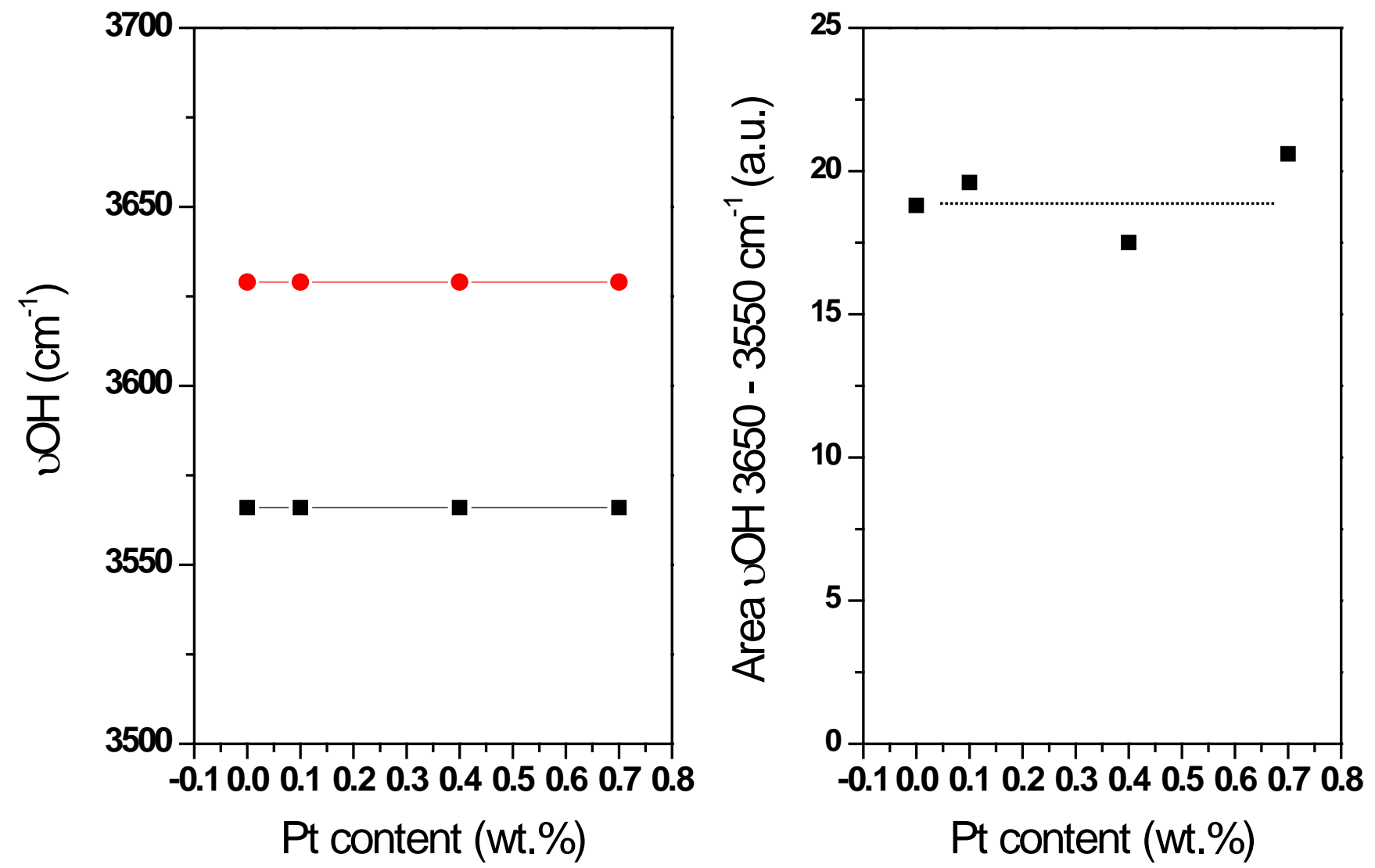

Figure 4. Evolutions of the positions and areas $\left(3650-3550 \mathrm{~cm}^{-1}\right)$ of the hydroxyl groups within the supercages and small cavities (at 3629 and $3566 \mathrm{~cm}-1$ ); left and right panels respectively. The semi-quantification has been done after normalization with the contribution due to silanol groups expected to be poorly affected by Pt atoms. 

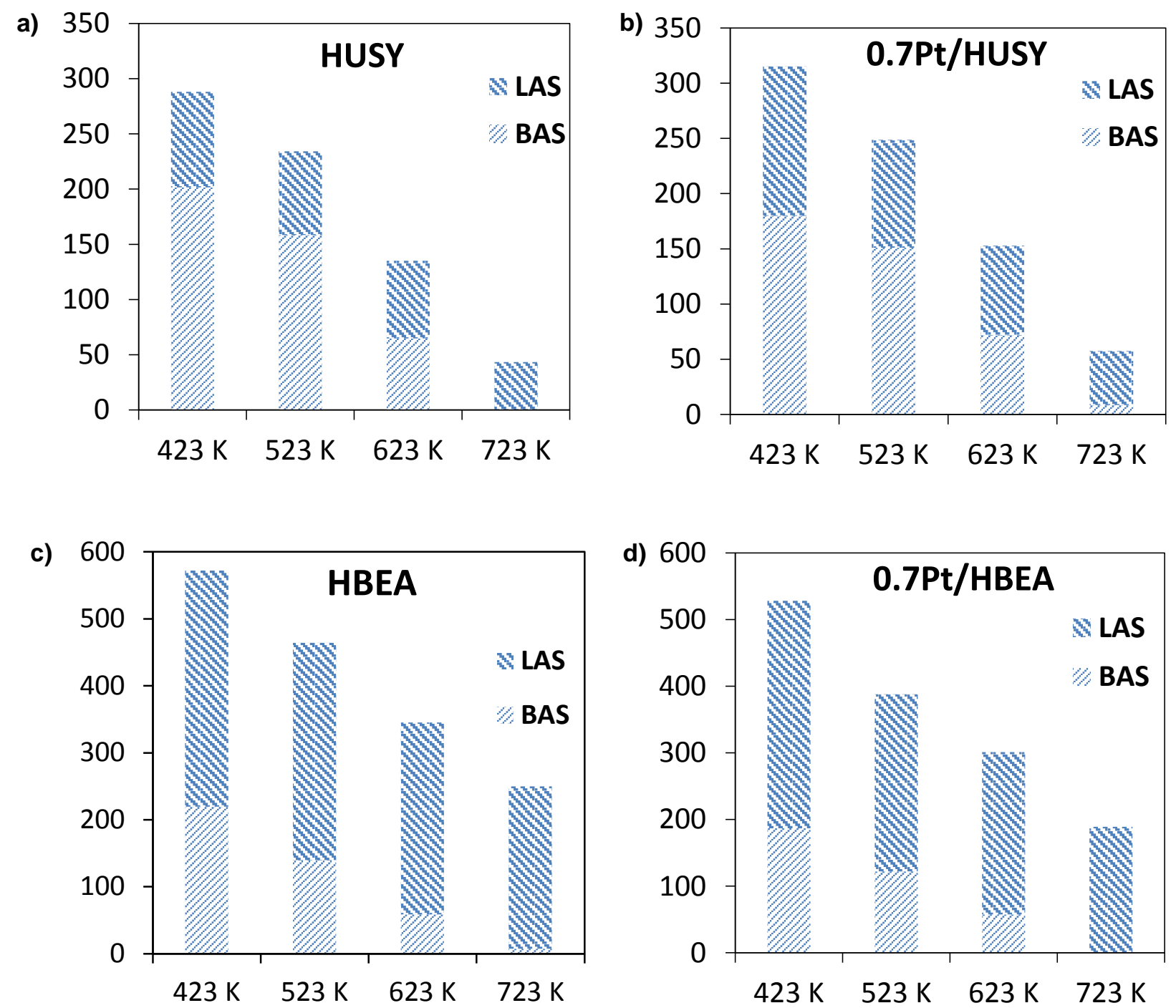

Figure 5. Concentrations (in $\mu \mathrm{mol} / \mathrm{g}$ ) of BAS and LAS sites on a) HUSY zeolite, b) 0.7Pt/HUSY, c) HBEA and d) $0.7 \mathrm{Pt} / \mathrm{HBEA}$ samples measured by pyridine thermodesorption followed by FTIR. 


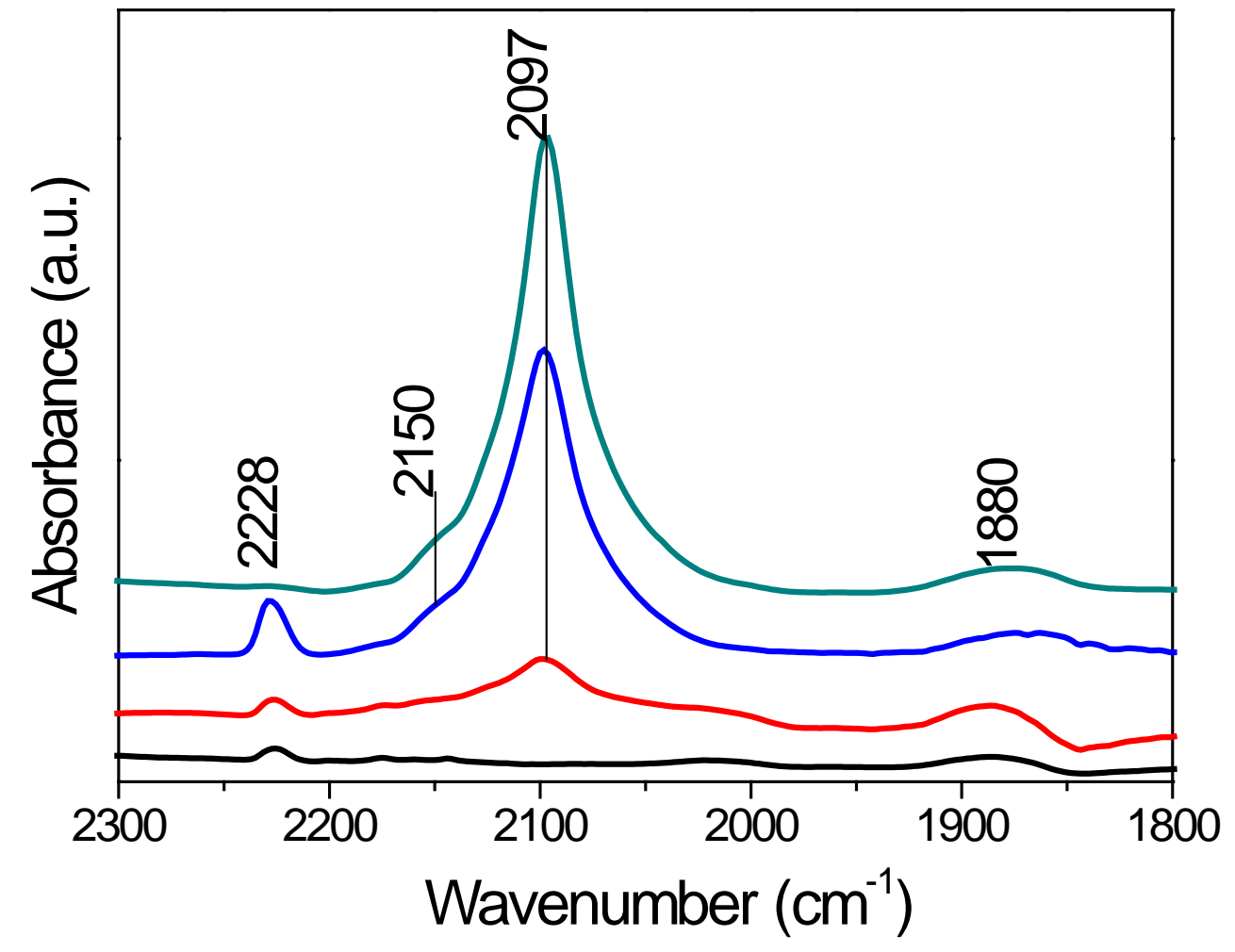

Figure 6. IR spectra of pre-reduced HUSY and Pt/HUSY catalysts at CO saturation. From top to bottom spectrum: $0.7,0.4,0.1$ and 0.0 wt.\% Pt. 


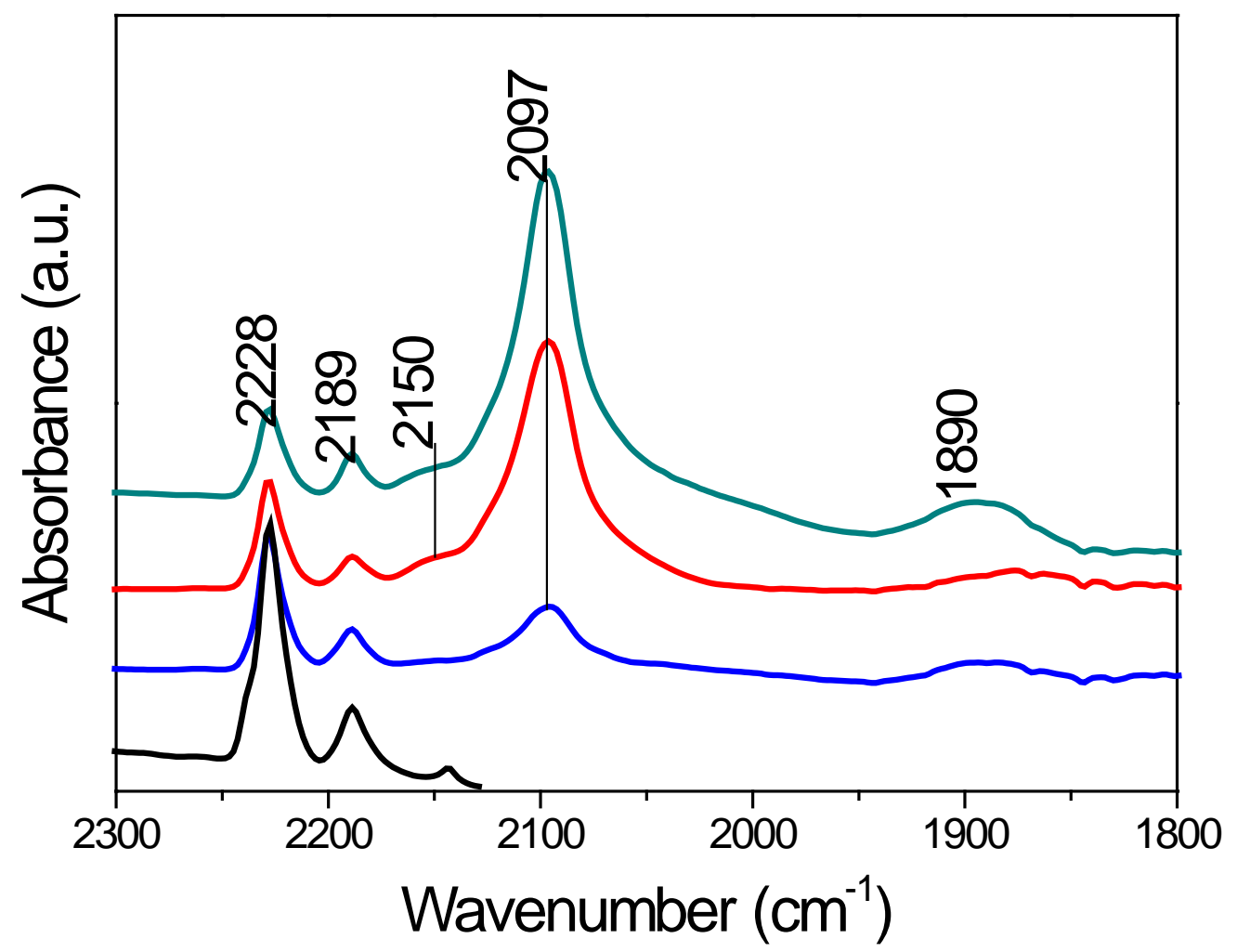

Figure 7. IR spectra of pre-reduced HBEA and Pt/HBEA catalysts at CO saturation. From top to bottom spectrum: $0.7,0.4,0.1$ and 0.0 wt.\% Pt. 


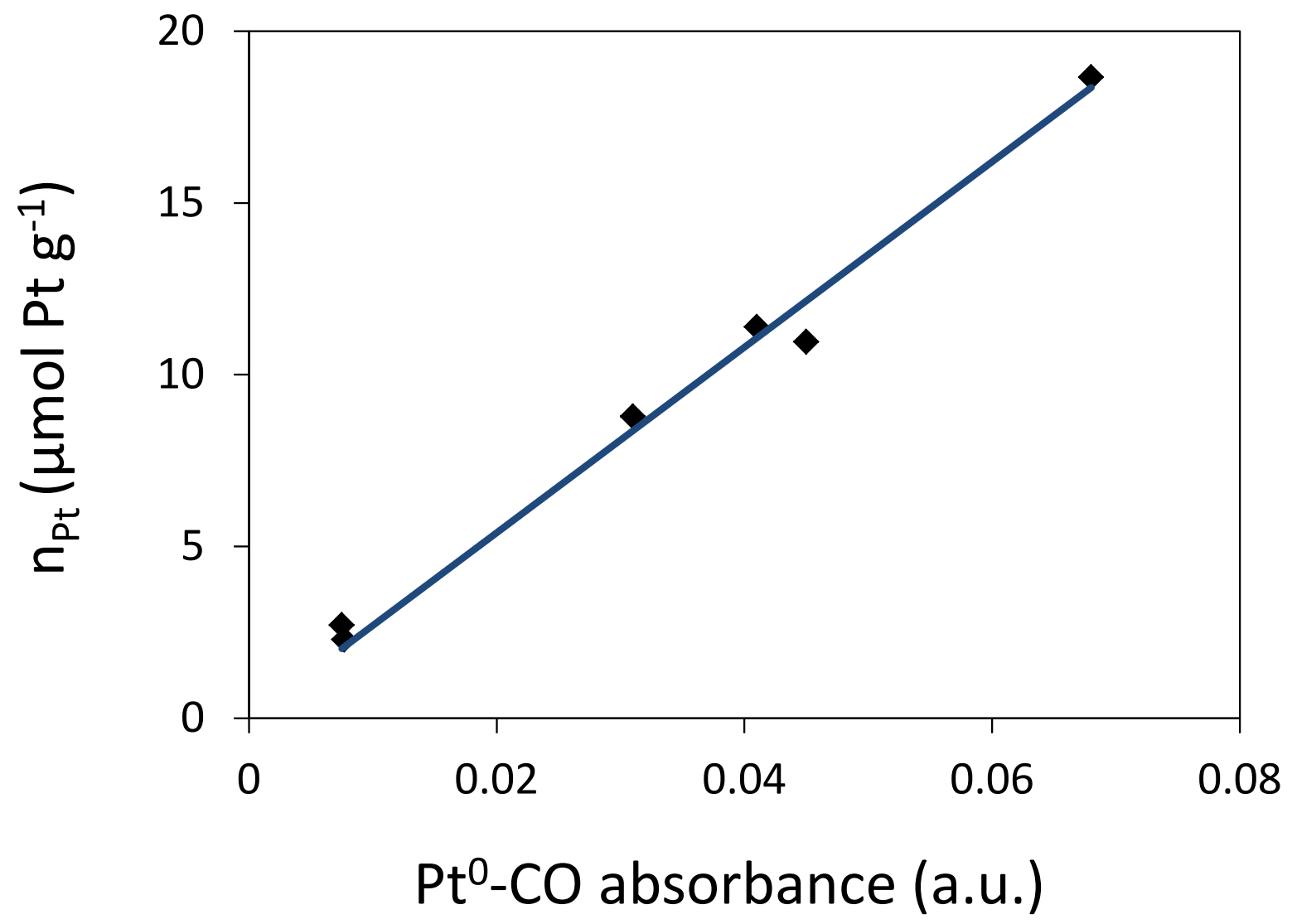

Figure 8. Number of Pt surface atoms measured by $\mathrm{H}_{2}-\mathrm{O}_{2}$ titration plotted as a function of the intensity of the $v_{\mathrm{CO}}$ at $2097 \mathrm{~cm}^{-1}$ from $\mathrm{Pt}^{\circ} \mathrm{CO}$ species for both series: HUSY and HBEA. 

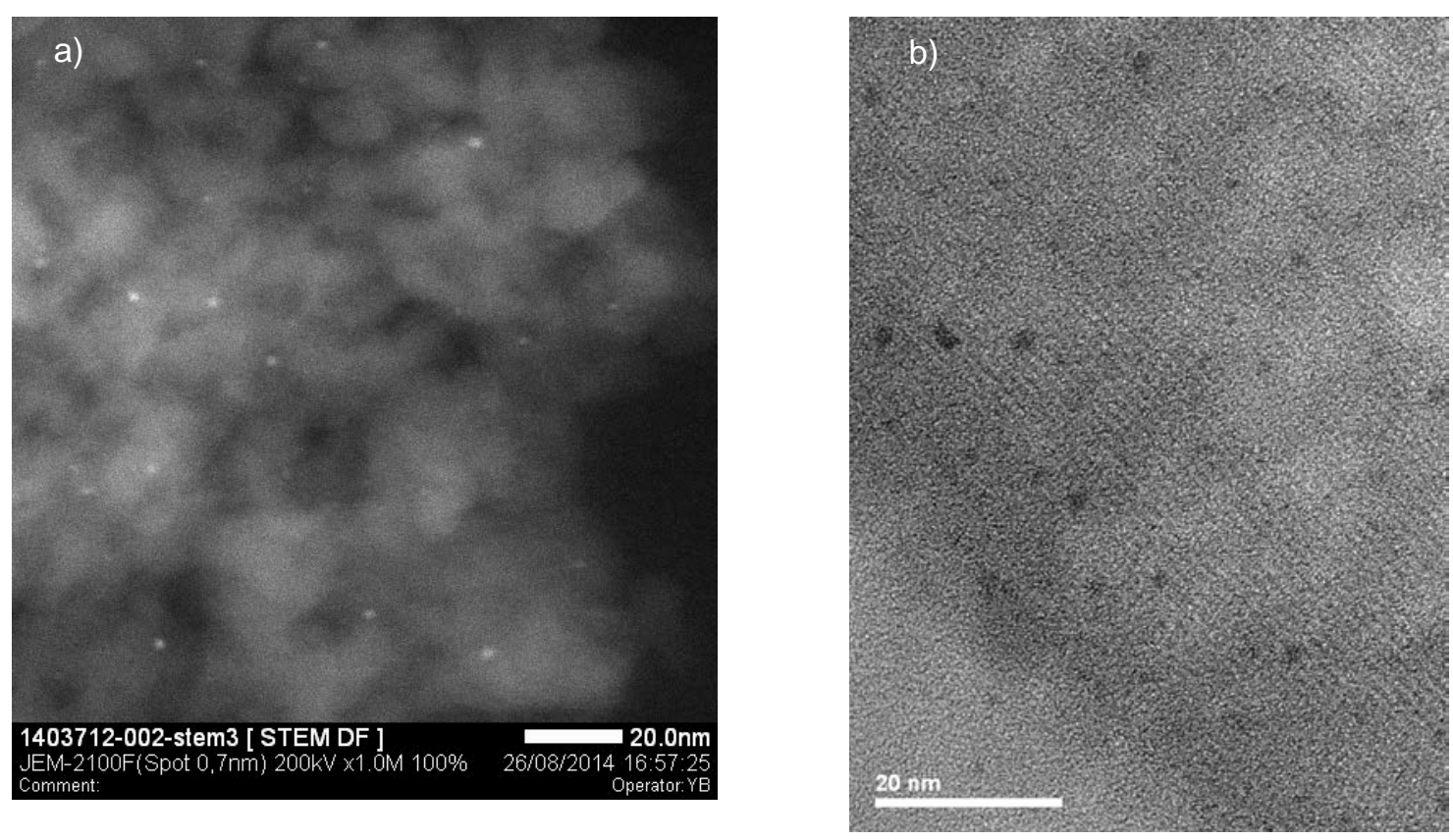

Figure 9. STEM micrograph for 0.1\%Pt/HBEA and TEM micrograph for $0.7 \% \mathrm{Pt} / \mathrm{HUSY}$. 

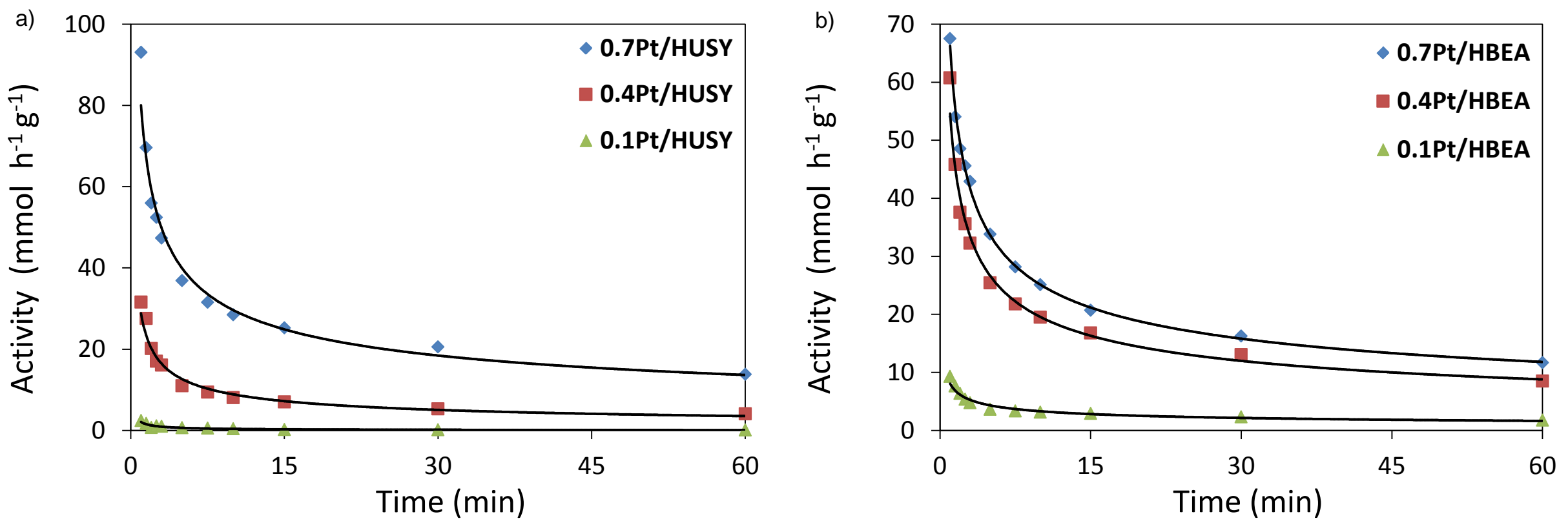

Figure 10. Activity as function of time-on-stream for a) Pt/HUSY and b) Pt/HBEA series in toluene hydrogenation. 

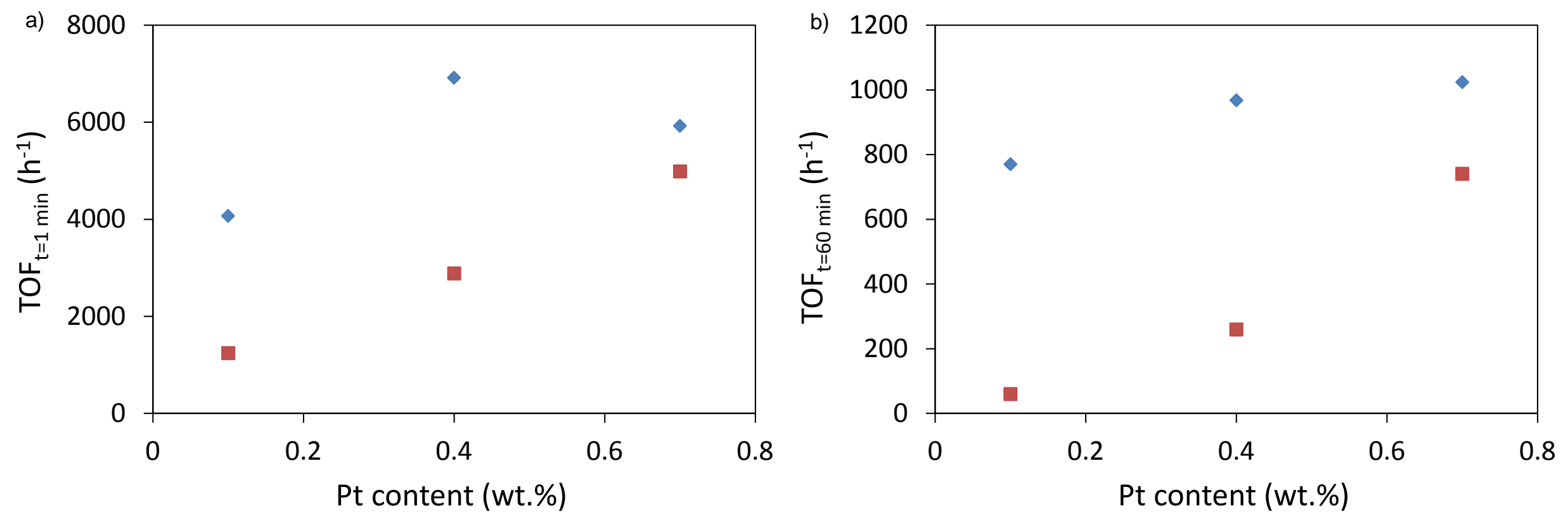

Figure 11. Turnover frequencies (per metal site) at a) $t=1$ min and b) $t=60$ min as function of Pt content for Pt/HBEA ( $\diamond$ ) and Pt/HUSY ( $\square$ ) series in toluene hydrogenation. 


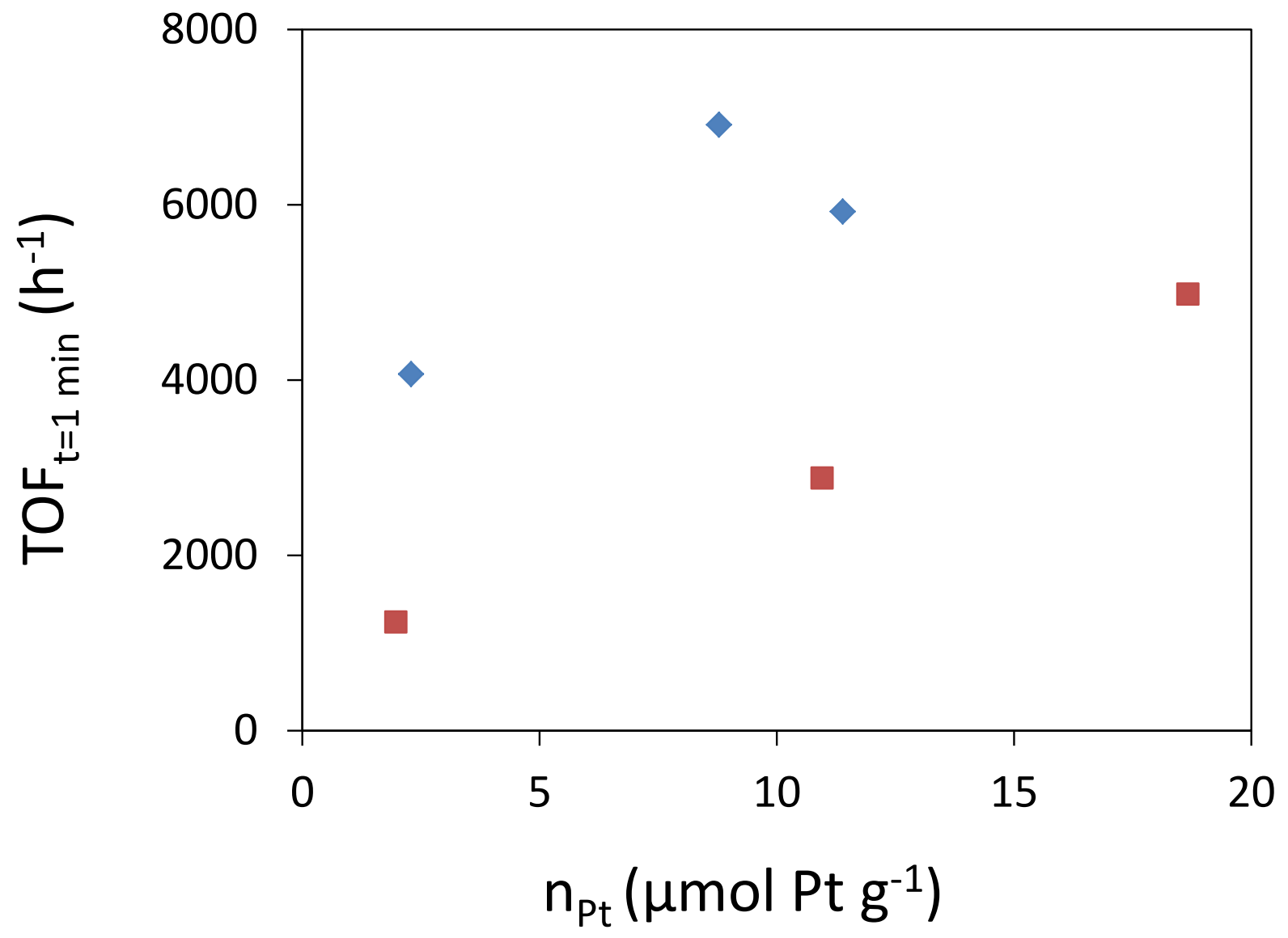

Figure 12. Turnover frequency (per metal site) at $t=1$ min as function of the number accessible Pt for $\mathrm{Pt} / \mathrm{HBEA}(\diamond)$ and $\mathrm{Pt} / \mathrm{HUSY}(\square)$ series in toluene hydrogenation. 


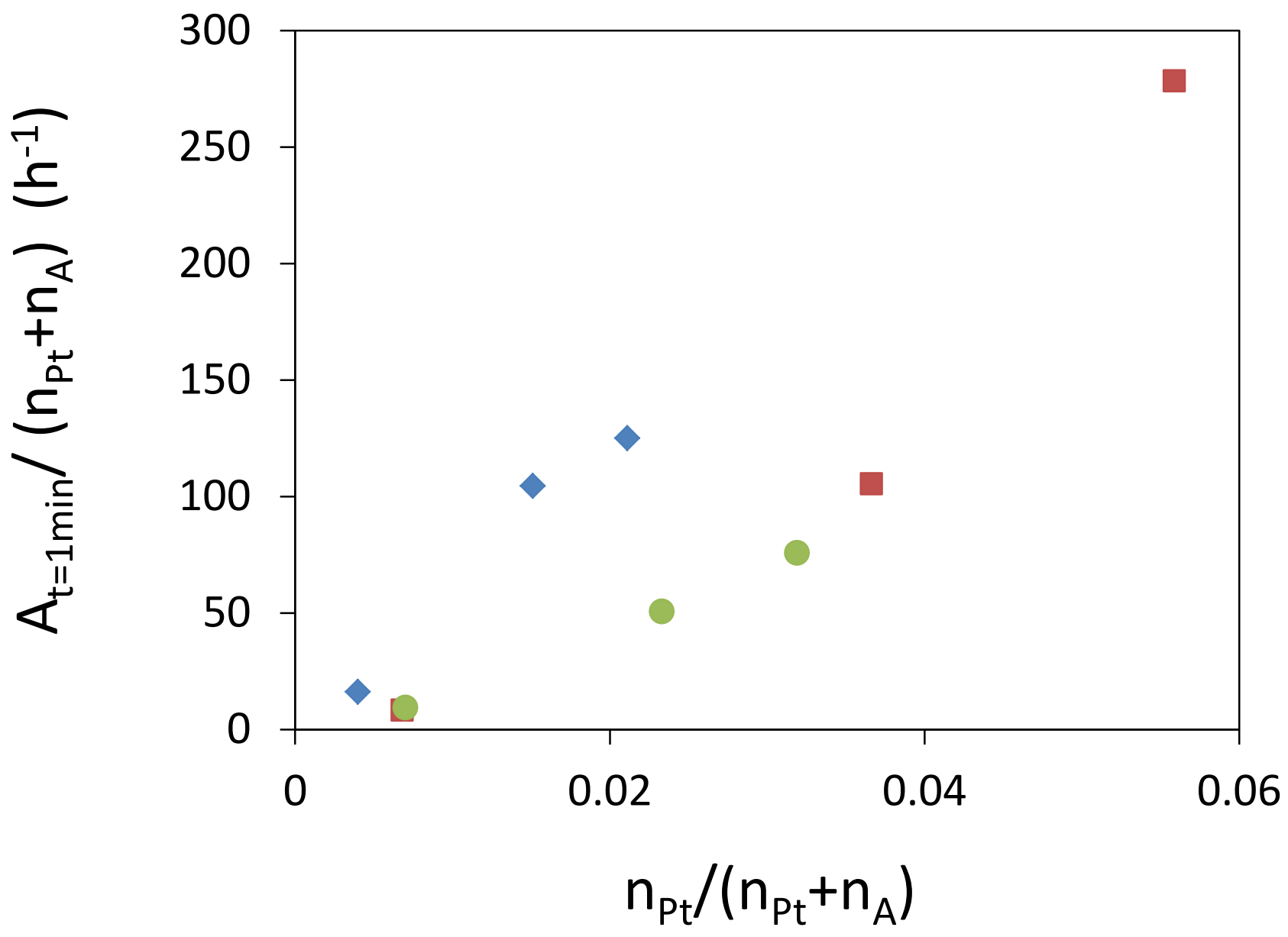

Figure 13. Activity per total adsorbing site as function of $n_{P t} /\left(n_{P t}+n_{A}\right)$ for Pt/HBEA $\left.\diamond\right)$ and Pt/HUSY $\left.\square\right)$ series in toluene hydrogenation. A series of $\mathrm{Pt} / \mathrm{HUSY}$ (Oalysts ( ) from Chupin et al. [33] were also included. 